\title{
Measurements of Parachute Dynamics in the World's Largest Wind Tunnel by Stereo Photogrammetry
}

\author{
Edward T. Schairer, ${ }^{1}$ Laura K. Kushner, ${ }^{2}$ and James T. Heineck ${ }^{3}$ \\ NASA Ames Research Center, Moffett Field, CA, 94035, USA \\ and \\ Eduardo Solis 4 \\ Science and Technology Corp., Moffett Field, CA, 94035, USA
}

Between 2012 and 2017, parachutes for four NASA Projects were tested in the 80- by 120 Ft test section of the National Full-Scale Aerodynamic Complex (NFAC) at NASA Ames Research Center. These projects were: (1) Low-Density Supersonic Decelerator (LDSD); (2) Capsule Parachute Assembly System (CPAS, for Orion); (3) Interior Exploration using Seismic Investigations, Geodesy and Heat Transport (InSight, a Mars mission); and (4) Mars 2020. In all tests stereo photogrammetry was used to measure time-dependent positions of features on the canopies. For the LDSD and CPAS tests, where the purpose was to study the trade-off between stability and drag of different parachute designs, the pendulum motion of the canopies about the riser attachment point was measured by calibrated cameras in the diffuser. The CPAS test also included static measurements where the inflated parachutes were pulled to the side by a system of tethers. The Insight tests were structural qualification tests where each canopy was packed in a bag and launched from a mortar. Cameras in the diffuser measured the trajectory of the bag and the stripping of the bag from the canopy. The Mars 2020 test was a workmanship verification test where the canopies were either launched from a mortar or deployed from a sleeve stretched along the tunnel axis. The deployments were recorded from many directions by thirteen high-speed cameras distributed in the diffuser and test section. Photogrammetry was not planned; however, after a tunnel-related accident ended the test prematurely, photogrammetric measurements were bootstrapped from the images to support the accident investigations. This paper describes how the photogrammetry measurements were made in each test and presents typical results.

\section{Nomenclature}

$C_{A} \quad=$ axial force coefficient (force along parachute axis)

$C_{N} \quad=$ normal force coefficient (force perpendicular to parachute axis and in plane of axis and free-stream)

$D_{0} \quad=$ nominal parachute diameter (diameter based on area of parachute when laid out flat)

$D_{p} \quad=$ projected parachute diameter (diameter based on frontal area when inflated)

$L_{1-11}=$ coefficients of Direct Linear Transformation

$q \quad=$ dynamic pressure

$r \quad=\quad$ radial distance from parachute axis

$R=$ distance from riser attachment point (pivot) to parachute vent

$t \quad=$ time

$U \quad=$ free-stream velocity

$x, y=$ horizontal and vertical image-plane coordinates (pixels)

$X, Y, Z \quad=$ stream-wise, lateral, and vertical object-space coordinates, origin at pivot

$\alpha_{G} \quad=$ geometric angle of attack (angle between parachute axis and tunnel stream-wise axis)

$\Phi=$ clock angle (angle from vertical of parachute axis projected into $Y$ - $Z$ plane)

\footnotetext{
${ }^{1}$ Aerospace Engineer, Experimental Aero-Physics Branch.

${ }^{2}$ Instrumentation Engineer, Wind Tunnel Systems Branch, AIAA Member.

${ }^{3}$ Physical Scientist, Experimental Aero-Physics Branch.

${ }^{4}$ Research Engineer, Aeromechanics Office.
} 


\section{Introduction}

$\mathrm{P}$ ARACHUTES for four NASA programs were recently tested in the 80- by 120-Ft test section of the National Full-Scale Aerodynamic Complex (NFAC) at NASA Ames Research Center. In each test, the time-varying positions of the parachutes were measured by stereo photogrammetry. The first test was for the Low-Density Supersonic Decelerator (LDSD) Project [1]. This project was developing Mars-entry decelerator systems for large payloads that includes both an inflatable aerodynamic decelerator and a supersonic parachute. A goal of the LDSD project was to improve the state-of-the-art of supersonic parachute design. To date, all Mars landers-from Viking I and II in 1976 to Mars Science Laboratory in 2012 - have used the same parachute design-Disk-Gap-Band (DGB) - to decelerate from supersonic to subsonic speeds. The purpose of the NFAC tests was to compare the performance (drag and stability) of other parachute designs - in particular Ringsail and Ringsail-like parachutes - to the performance of DGB parachutes and down-select a design for future testing at full scale in supersonic flight. Thirteen $38 \%$-scale parachute configurations were tested. The riser for each parachute was attached to the top of a strut near the upstream end of the test section, and the time history of the position of the parachute vent, which was near the downstream end of the test section, was measured by two cameras mounted in the diffuser. The tests were conducted during two tunnel entries, the first in late 2012 and the second in early 2013.

The second test supported development of the Capsule Parachute Assembly System (CPAS) for the Orion spacecraft [2]. CPAS is designed to decelerate the Orion vehicle during the final stage of re-entry through the Earth's atmosphere. The system includes eleven parachutes that deploy sequentially beginning with three parachutes that pull off Orion's forward bay cover and ending with inflation of three large main chutes. The test in NFAC was conducted in preparation for drop tests to identify modifications to the main parachutes that would improve stability without decreasing drag. Of particular concern was undesirable pendulum motion observed during earlier drop tests of a mock capsule under two parachutes. Three 35\%-scale parachutes were tested. Modifications to the canopies included changes in the distribution of porosity, reefing, and suspension line lengths. The test configuration for the CPAS was very similar to that used for LDSD. The principal difference was that most CPAS runs included "static" test points where a system of tethers pulled the inflated canopy laterally through a sequence of angles of attack. After the last static point, the tethers were released and "free-flight" data were acquired. The CPAS tests occurred in early 2015.

The third test was for the Interior Exploration using Seismic Investigations, Geodesy and Heat Transport (InSight) mission to Mars, launched on May 5, 2018 and scheduled to land November 26, 2018 [3]. This mission will place a geophysical lander on Mars to study the planet's deep interior. Upon entry in the Martian atmosphere the vehicle will be decelerated from supersonic to subsonic speeds by a DGB parachute. Full-scale parachutes for this mission were tested during two entries in NFAC, the first in early 2015, immediately after the CPAS test, and the second in late 2015. During both entries, the parachutes were packed in bags and fired from a mortar mounted atop the same strut as was used for the LDSD and CPAS tests. After the suspension lines were fully extended, they pulled the canopy out of the bag ("bag strip") and the canopy inflated. The first entry was conducted as part of a structural qualification program, and the deployments were documented by high-speed cameras. Photogrammetry was not required for this test; however, because the cameras used for CPAS were still in place, images from these cameras were also acquired and used to compute the trajectories of the bags. The high-speed imagery revealed that the canopies twisted as they were being pulled out of the bag, and there was concern that this twisting could interfere with proper inflation of the canopies. Therefore, the second entry was conducted to observe how a different method of packing the parachutes might affect this twisting and inflation of the canopies. The CPAS cameras were replaced by high-speed cameras that were calibrated for photogrammetry.

The fourth test was a workmanship verification test of full-scale parachutes for the Mars 2020 mission [4]. Mars 2020 is part of NASA's Mars Exploration Program and is very similar to the successful Mars Science Laboratory (MSL). It will use the same landing system, including a similar parachute, as MSL. The parachutes tested for Mars 2020 were significantly larger than the parachutes tested for LDSD, CPAS, or Insight, and they flew much further downstream - in the diffuser rather than near the downstream end of the test section. The parachutes were deployed either by firing from a mortar or by sleeve deployment whereby the canopy was wrapped in a narrow sleeve and stretched along the tunnel centerline. The deployments were recorded from many directions by 13 high-speed cameras fielded by teams from both Ames and JPL. Photogrammetry measurements were not planned; however, after a tunnelrelated accident ended the test prematurely, an effort was made to extract photogrammetric information from the images to support the accident investigations. 
The purpose of this paper is to describe how the photogrammetry measurements were made in each test and to present typical results. All of the tests had much in common. They are described in chronological order, with differences and how those differences were accommodated pointed out.

\section{Wind Tunnel and Test Section}

The National Full-Scale Aerodynamic Complex (NFAC [5], Fig. 1) is located at NASA Ames Research Center and is operated by the Air Force Arnold Engineering Development Center (AEDC). The NFAC includes two test sections powered by a single set of fans: an oval 40 - by 80 -ft test section that operates in closed-return mode; and a rectangular 80by 120 -Ft test section (the largest in the world) that is part of a non-return leg where outside air is drawn through a 5:1 contraction inlet and exhausted through louvers in the tunnel wall downstream of the fans. The drive system for both test sections consists of six 40$\mathrm{ft}$ diameter fans, each driven by a $23,500 \mathrm{hp}$ motor. Maximum airspeed in the 80 - by 120 -ft test section is approximately $100 \mathrm{kts}$.

The 80 - by 120 -ft test section is $192 \mathrm{ft}$ long. The

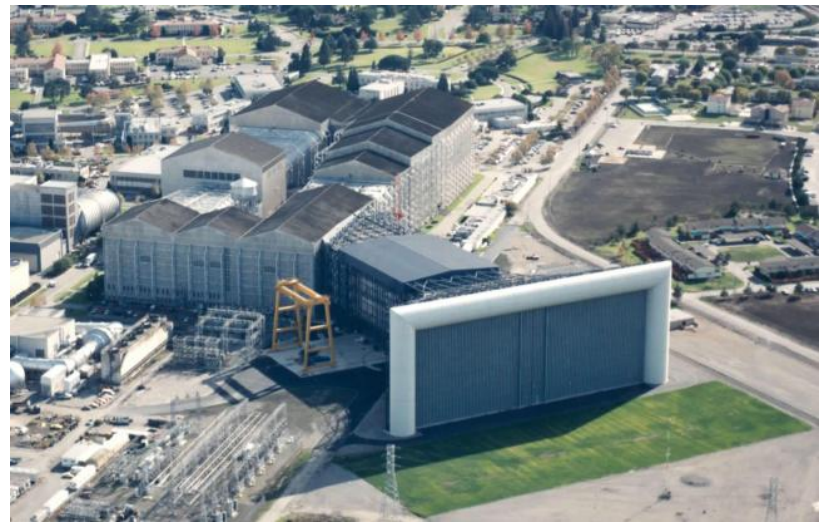

Fig. 1 National Full-Scale Aerodynamic Complex.

floor includes a 56-ft diameter turntable and "T-frame" to which struts that support the model are usually attached. Two strut carriages ride along the top of the " $T$ ", and their separation can be adjusted to accommodate different test articles. Downstream of the test section is a constant-area duct ("diffuser") that leads to turning vanes that direct the flow into the fans.

The floor and sidewalls of the test section are covered by perforated steel plates that absorb sound. One sidewall includes two 80 -ft tall doors that swing open to allow a nearly 100 - $\mathrm{ft}$ tall gantry crane to roll into the test section. The crane rolls on rails at ground level about 25 feet below the floor of the test section, so the top of the crane is less than 10 feet below the ceiling. Panels in the floor of the test section above the rails fold up to allow the legs of the crane to pass. The distance between the crane's upstream and downstream legs is 100 feet, and the lateral dimension at the floor of the test section is about $40 \mathrm{ft}$.

\section{Low Density Supersonic Decelerator}

Figure 2 shows the LDSD test configuration. The canopies flew horizontally near the downstream end of the test section with their risers attached to the top of a $40-\mathrm{ft}$ tall strut that was supported by the $\mathrm{T}$ frame. The turntable was rotated to place the strut on the tunnel centerline. The strut included an airfoil-shaped shroud. For the first entry, a circular fore-body was mounted to the strut just upstream of the riser attachment point to produce a wake representative of what a lander would produce. Images of the outer surface of the parachutes were acquired by two cameras that were mounted on the floor of the diffuser and pointed upstream. A third camera was mounted just below the top of the strut and was pointed straight downstream, but its images were never used for photogrammetry.

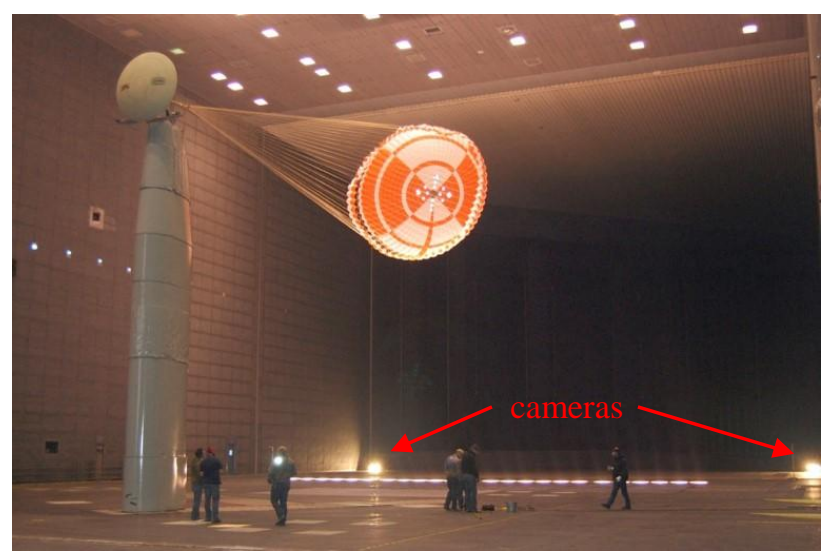

Fig. 2 LDSD test configuration. 


\section{A. Test Articles}

The parachutes were $38.7 \%$ of full scale and were sized to match a spare full-scale DGB parachute from the Mars Phoenix Scout program that was available for testing and that served as a baseline [6]. The nominal diameters $\left(D_{0}\right)$ were $38.7 \mathrm{ft}(11.8 \mathrm{~m})$, and the projected diameters $\left(D_{p}\right)$ were $0.7 \times D_{0}=27 \mathrm{ft}(8.26$ $\mathrm{m})$. The suspension line lengths were $1.7 \times D_{0}=65.8$ $\mathrm{ft}(20.1 \mathrm{~m})$. This geometry allowed lateral and vertical parachute angle excursions of $\pm 30^{\circ}$ and $\pm 20^{\circ}$, respectively (Fig. 3).

Thirteen canopies of six types were tested. In addition to a second DGB parachute that was a replica of the spare Phoenix parachute but constructed of a lower-permeability nylon, the other parachutes were Ringsail (RS) and variations on the RingSail design. All of the parachutes except the Phoenix spare were constructed of low-permeability Nylon, and all were built by Pioneer Aerospace.

Four 2.5-inch diameter retro-reflective targets were sewn to both the inner and outer surfaces of the first ring surrounding the vent, and four coded targets were sewn in the third ring. The coded targets were created by silk-screening a black pattern over an over-size circular target (Fig. 4).

\section{B. Cameras and Lamps}

The cameras were Dalsa 4M60 that acquired 4
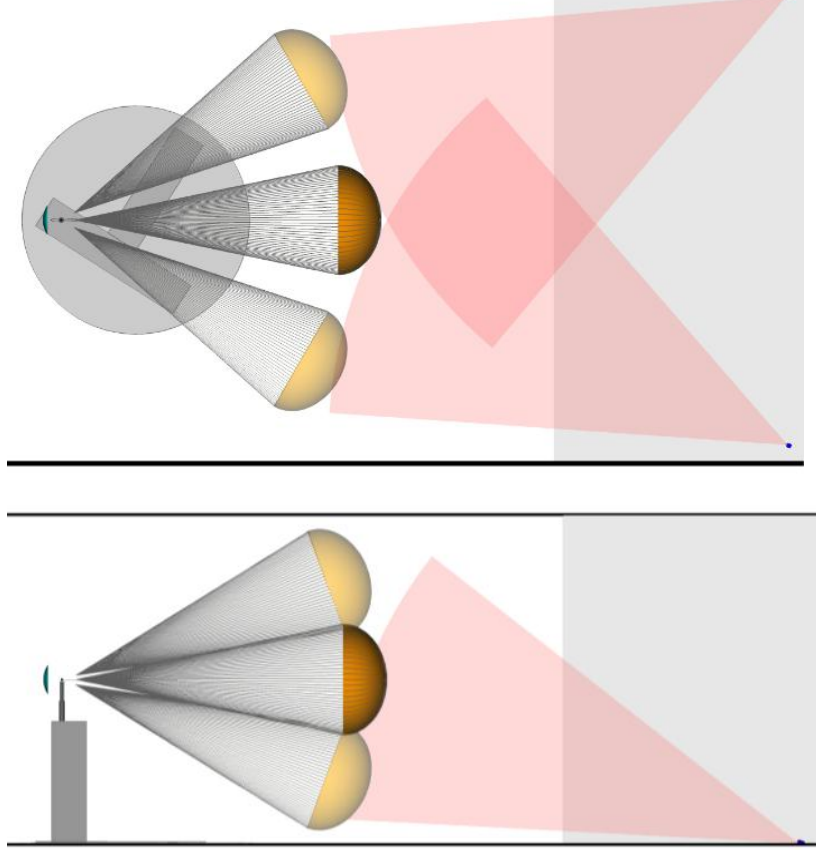

Fig. 3 Top (upper) and side (lower) views showing range of canopy positions and camera fields of view.

Mega-pixel images (2352 x 1728 pixels) at $60 \mathrm{~Hz}$. The cameras were externally driven by a digital signal generator and were controlled from a computer located just outside the test-section. Image data were transmitted from the cameras to digital video recorders (DVR) across fiber optic cables. Images from the DVRs were downloaded to the computer between runs. Lens selection, placement, and pointing of the cameras was planned well in advance of the

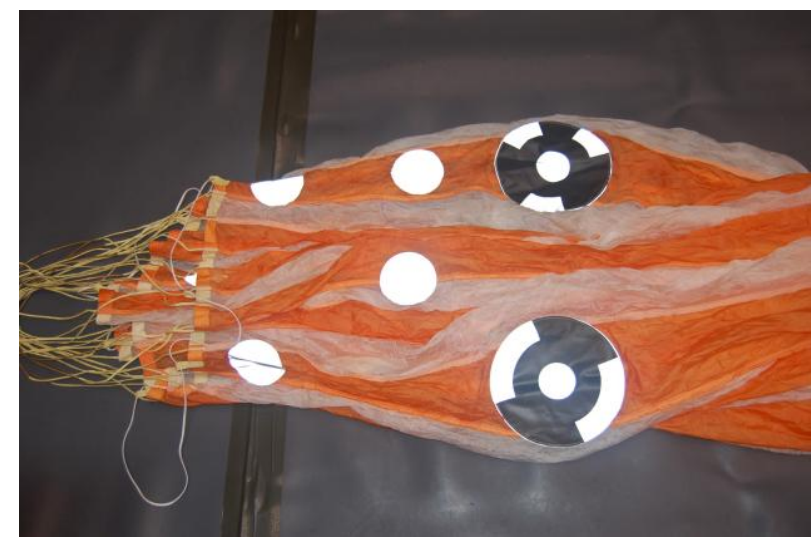

Fig. 4 Coded retro-reflective targets on LDSD canopy.

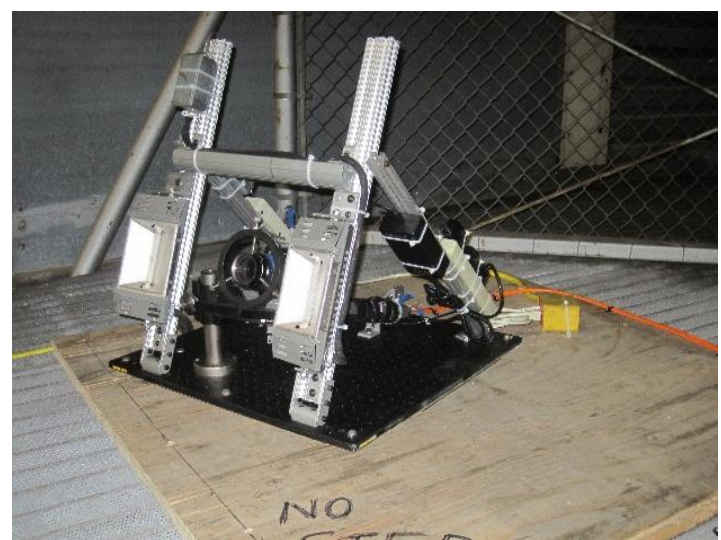

Fig. 5 Camera and lamp installation.

test using virtual imaging software [7, 8]. Two continuous, high-intensity $(1000 \mathrm{~W})$ halogen lamps were mounted next to each of the downstream cameras, one on each side (Fig. 5). This maximized light return from the retro-reflective targets on the canopies. The cameras and lamps in the diffuser were not behind shrouds and thus were exposed to the airflow. 
Several strobe lights were placed in the test section where they would appear in the images from the cameras. The strobes were triggered to flash once shortly after data acquisition began. The triggering pulse was also recorded by the tunnel data acquisition system (DAS). The appearance of the strobe in the images was used to verify that the cameras were synchronized.

\section{Camera Calibration}

The Direct Linear Transformation (DLT) was used to map points from 3D object space $(X, Y, Z)$ to the 2D image plane $(x y)$ of each camera [9]:

$$
\begin{aligned}
& x=\frac{L_{1} X+L_{2} Y+L_{3} Z+L_{4}}{L_{9} X+L_{10} Y+L_{11} Z+1}+\Delta x_{\text {lens }} \\
& y=\frac{L_{5} X+L_{6} Y+L_{7} Z+L_{8}}{L_{9} X+L_{10} Y+L_{11} Z+1}+\Delta y_{\text {lens }}
\end{aligned}
$$

$\Delta x_{\text {lens }}$ and $\Delta y_{\text {lens }}$ are nonlinear terms that correct for lens distortion. The eleven DLT coefficients, $L_{1}-L_{11}$, of each camera were determined by calibration.

Each camera was calibrated after it had been positioned, pointed, and focused by acquiring one or more images that included $n$ targets whose 3D spatial coordinates were known. After the image-plane coordinates of these targets were determined from the image(s), the DLT coefficients were computed from [10]:

$$
\left[\begin{array}{ccccccccccc}
X_{1} & Y_{1} & Z_{1} & 1 & 0 & 0 & 0 & 0 & x_{1} X_{1} & x_{1} Y_{1} & x_{1} Z_{1} \\
X_{2} & Y_{2} & Z_{2} & 1 & 0 & 0 & 0 & 0 & x_{2} X_{2} & x_{2} Y_{2} & x_{2} Z_{2} \\
\vdots & \vdots & \vdots & \vdots & \vdots & \vdots & \vdots & \vdots & \vdots & \vdots & \vdots \\
X_{n} & Y_{n} & Z_{n} & 1 & 0 & 0 & 0 & 0 & x_{n} X_{n} & x_{n} Y_{n} & x_{n} Z_{n} \\
0 & 0 & 0 & 0 & X_{1} & Y_{1} & Z_{1} & 1 & y_{1} X_{1} & y_{1} Y_{1} & y_{1} Z_{1} \\
0 & 0 & 0 & 0 & X_{2} & Y_{2} & Z_{2} & 1 & y_{2} X_{2} & y_{2} Y_{2} & y_{2} Z_{2} \\
\vdots & \vdots & \vdots & \vdots & \vdots & \vdots & \vdots & \vdots & \vdots & \vdots & \vdots \\
0 & 0 & 0 & 0 & X_{n} & Y_{n} & Z_{n} & 1 & y_{n} X_{n} & y_{n} Y_{n} & y_{n} Z_{n}
\end{array}\right] \times\left[\begin{array}{c}
L_{1} \\
L_{2} \\
L_{3} \\
L_{4} \\
L_{5} \\
L_{6} \\
\vdots \\
L_{11}
\end{array}\right]=\left[\begin{array}{c}
-x_{1} \\
-x_{2} \\
\vdots \\
-x_{n} \\
-y_{1} \\
-y_{2} \\
\vdots \\
-y_{n}
\end{array}\right]
$$

For six or more targets, this is an over-determined set of linear equation that can be solved in a least-squares sense for the coefficients $L_{1-11}$. The targets cannot all lie in the same plane and they should be well distributed in the field of view. The set of equations is usually ill-conditioned and must be solved by singular value decomposition [11].

Distributing targets in the huge region of interest and measuring their spatial coordinates were the greatest challenges that had to be overcome to apply photogrammetry in the NFAC 80 - by 120 -ft test section. All of the authors' previous applications of photogrammetry in wind tunnels had been at a much smaller scale where it was easy and economical to build a calibration object with precisely defined targets that could be accurately positioned in the region of interest. In the only previous use of photogrammetry in the NFAC 80 - by 120 -ft test section, Styrofoam balls suspended on ropes from the ceiling of the test section were used as calibration targets [12]. Air currents in the test section and small pendulum motion of the ropes contributed to uncertainty (up to \pm 3 inches) in the spatial positions of the balls.

The LDSD parachutes flew with their vents just downstream of the position of the downstream legs of the crane when the crane was in the test section (Fig. 6). Although the crane was much narrower (40 feet wide at its base) than the test section, it could be moved laterally to within about 10 feet of each sidewall. Therefore, since it occupied much of the same space as the parachutes, the crane was a natural choice to support calibration targets.

Targets three inches in diameter were cut from sheets of retro-reflective material and applied by means of adhesive backing to 3-in squares of flexible, magnetized sheet rubber. These targets adhered well to the steel crane; they were easy to apply and remove and maintained their positions when the crane was moved. Targets were distributed on the downstream legs and cross-bar of the crane up to a height that could be reached from a scissors lift—about 50 feet above the floor. Targets on the inboard and outboard faces of the legs provided the out-of-plane points needed to compute a DLT. The space coordinates of all targets were measured using a commercial photogrammetry system, Video Simultaneous Triangulation and Resection System (V-STARS) [13]. By this approach, the targets did not need to be precisely placed at known locations - they just needed to be well distributed.

With the V-STARS system, images of our retro-reflective targets were acquired from many directions using a special, precisely self-calibrated camera. Images were acquired from the floor of the test section and from the scissors 


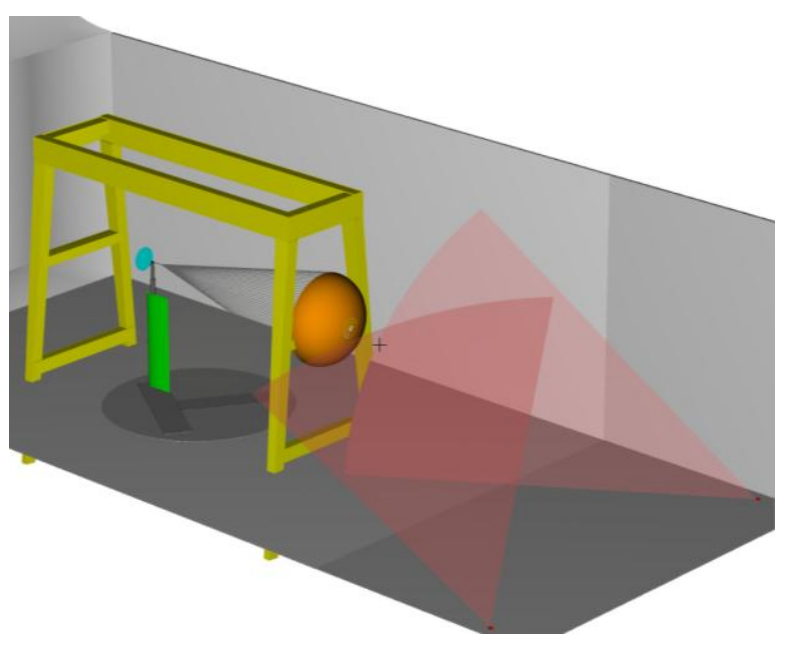

Fig, 6 Schematic showing crane and canopy.

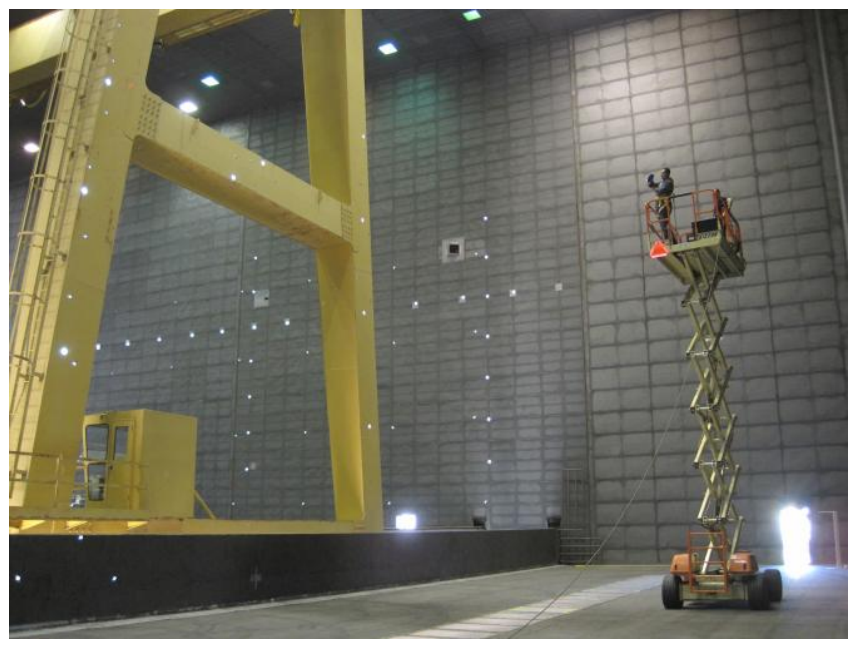

Fig. 7 Measuring calibration targets by V-STARS.

lift at several heights (Fig. 7). In addition to the calibration targets, coded targets were distributed on the crane and the floor of the test section. These targets were recognized by the V-STARS software and were used to stitch together the many views from the V-STARS camera and triangulate the target locations. At least 50 images included two scale bars and a "crucifix" that established the V-STARS coordinates system. Targets were also placed on several reference points ("monuments") in the floor of the test section and were used to transform the V-STARS measurements to tunnel coordinates.

To fully span the region of interest a complete set of V-STARS images was acquired with the crane in three lateral positions: one on centerline and one near each sidewall (Fig. 8). Images of the crane at each position were also acquired with the photogrammetry cameras. Data from images of the crane in all three positions were combined to compute a single calibration for each camera. Targets were also placed on both sidewalls and measured by V-STARS. These targets, however, were not used in the calibrations.

This was the largest V-STARS "shoot" ever accomplished at Ames, and several days were required to complete it. Considerable effort was required to apply and remove targets, especially those high up on the crane. This effort, however, produced coordinates of hundreds of well-distributed targets with an RMS uncertainty of less than 0.01 in. A satisfactory calibration of the strut-mounted camera was never achieved because, from its position, too few out-ofplane targets were visible. Therefore, all measurements were based on images from the two downstream cameras only.

\section{Data Acquisition}

At the beginning of each run, with the wind off, the riser and suspension lines were draped down from the top of the strut to the canopy, which lay on a protective vinyl floor covering downstream of the strut. As airspeed in the test section was brought up, the parachute inflated and rose from the floor. Once the airspeed reached the desired test condition (usually 15 or $25 \mathrm{kts}$ ), a verbal cue was given and the photogrammetry cameras were manually commanded to begin recording images. Recording continued, usually for three minutes, but sometimes for as long as six minutes, until the run was over. As the airspeed was reduced, the canopy deflated and collapsed to the floor. Images were

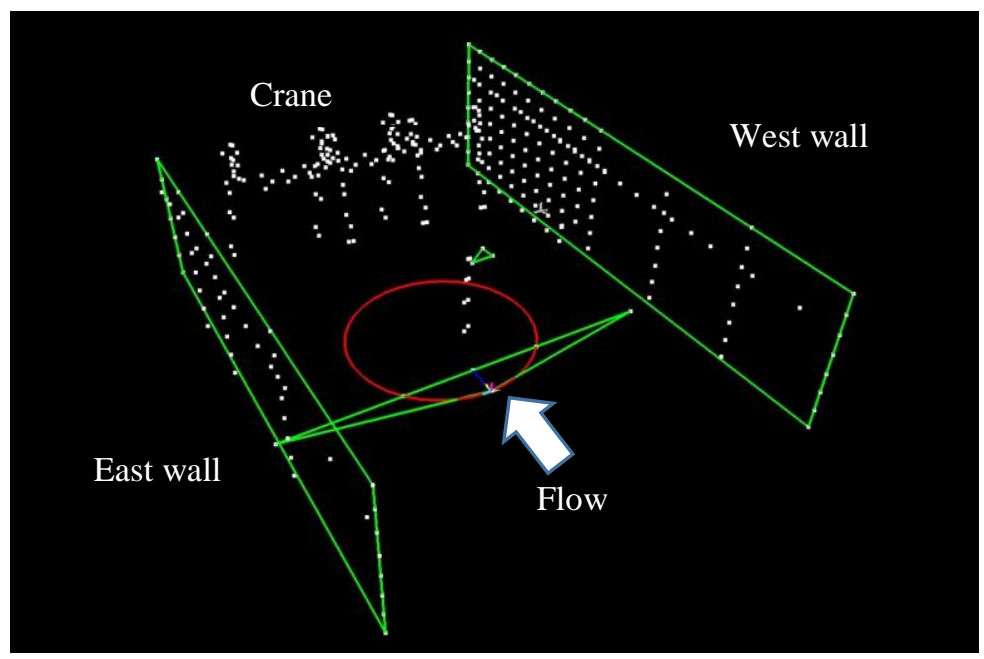

Fig. 8 Processed V-STARS data show targets in the test section. 
downloaded from the DVRs to the computer as time permitted - usually at the end of the shift.

\section{E. Data Analysis}

Images from the cameras were analyzed using image-analysis and photogrammetry software developed in house. The software runs on personal computers under the Windows operating systems and has functions for performing a wide variety of tasks. These include: reading sequences of images; locating targets or other points of interest in the images either automatically using a target-finding algorithm or manually by "point and click" with the computer mouse; editing targets that have been incorrectly located; computing camera calibrations; computing space coordinates of targets from their image-plane coordinates; and plotting the position time-history of a single target or the spatial coordinates of multiple targets at a single instance.

The four targets on the inner-most ring surrounding the vent were manually identified in the first two images from each camera using the computer mouse. Coded targets on a ring surrounding these targets were used to establish the correspondence of targets between cameras. Then, an automatic target-finding algorithm tracked the targets in each subsequent image in each sequence. At each step, the algorithm first estimated the expected position of each target from the target's positions in the previous two images. Then the algorithm searched for the target in an interrogation window centered on the expected position. By this procedure it was possible to track targets over a wide range of positions even when their displacements from one image to the next were much larger than size of the interrogation window. The position of the vent in each image was assumed to be the average of the four targets that surrounded it.

The position of the vent in 3D object space $(X, Y, Z)$ at each instance was computed from the 2D image-plane coordinates from both cameras $\left(x^{A}, y^{A}\right.$ and $\left.x^{B}, y^{B}\right)$ and the camera calibration coefficients $\left(L^{A}\right.$ and $\left.L^{B}\right)$ :

$$
\left[\begin{array}{lll}
x^{A} L_{9}^{A}-L_{1}^{A} & x^{A} L_{10}^{A}-L_{2}^{A} & x^{A} L_{11}^{A}-L_{3}^{A} \\
y^{A} L_{9}^{A}-L_{5}^{A} & y^{A} L_{10}^{A}-L_{6}^{A} & y^{A} L_{11}^{A}-L_{7}^{A} \\
x^{B} L_{9}^{B}-L_{1}^{B} & y^{B} L_{10}^{B}-L_{2}^{B} & x^{B} L_{11}^{B}-L_{3}^{B} \\
y^{B} L_{9}^{B}-L_{5}^{B} & y^{B} L_{10}^{B}-L_{6}^{B} & y^{B} L_{11}^{B}-L_{7}^{B}
\end{array}\right] \times\left[\begin{array}{c}
X \\
Y \\
Z
\end{array}\right]=\left[\begin{array}{l}
L_{4}^{A}-x^{A} \\
L_{8}^{A}-y^{A} \\
L_{4}^{B}-x^{B} \\
L_{8}^{B}-y^{B}
\end{array}\right]
$$

This is an over-determined set of linear equations that was solved in a least-squares sense for $(X, Y, Z)$. The leastsquares solution was computed by singular value decomposition. The origin of coordinates was the riser attachment point at the top of the strut.

\section{F. Results}

The test program included 72 runs: 26 in the first entry, and 46 in the second. Most runs included test points at both $U=15$ and $25 \mathrm{kts}$. At each test point, photogrammetry yielded the time history of the position on the vent.

Figure 9 shows a pair of photogrammetry images from a typical run. In their raw form, everything in the images was very dark except for the bright retro-reflective targets, the ceiling lamps, and daylight through the inlet guide vanes. The images have been brightened here to allow the canopy to be seen. A red dot in each image shows the position of the vent computed from the surrounding targets. The time history of the position of the vent was determined from thousands of such image pairs at each test condition: at least 10,800 pairs for three-minute data points and twice that number for six-minute points. Figure 10 shows stream-wise $(X)$, lateral $(Y)$, and vertical $(Z)$ vent-position measurements for the first 60 seconds of a typical six-minute run (Ringsail canopy, $25 \mathrm{kts}$ ). Also shown is the distance of the vent from the riser attachment point $(R)$. The oscillations in the lateral and vertical directions are sinusoidal and very similar to each other, both in amplitude and frequency. Axial oscillations ( $X$ and $R$ ) are smaller and occur at higher frequencies.

Time traces of clock angle $(\Phi)$ versus total geometric angle of attack $\left(\alpha_{G}\right)$ from runs of the four types of canopies are presented in Fig 10. The high-permeability DGB parachute exhibited much smaller excursions in total angle of attack $\left(\alpha_{G}<10^{\circ}\right)$ than any of the others. All of the canopies show a slight downward bias, probably due to gravity. Figure 11 also shows histograms of geometric angle of attack for the same four cases. All of the canopies trim at nonzero $\alpha_{G}$. The peak of the DGB histogram occurs at about $7^{\circ}$, considerably lower than for the other canopies.

Note that $\alpha_{G}$ is the total geometric angle of attack, not the total angle of attack, which includes the angle induced by the angular velocity of the canopy. In Ref. [14], the total angle of attack is computed and used to estimate the dynamic stability of the parachutes by Schoenenberger's method [15]. Comprehensive accounts of results from the LDSD tests are contained in Refs. [6, 16]. 

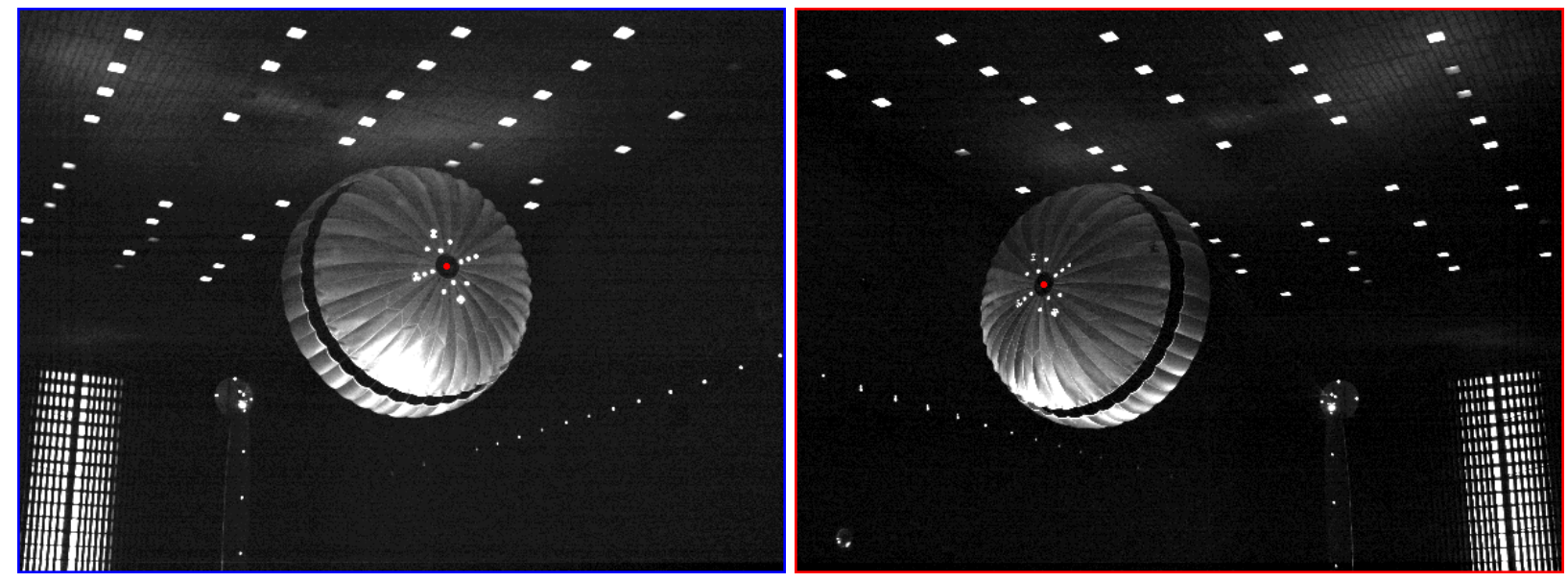

Fig. 9 Typical images of LDSD DGB canopy from cameras in the diffuser.
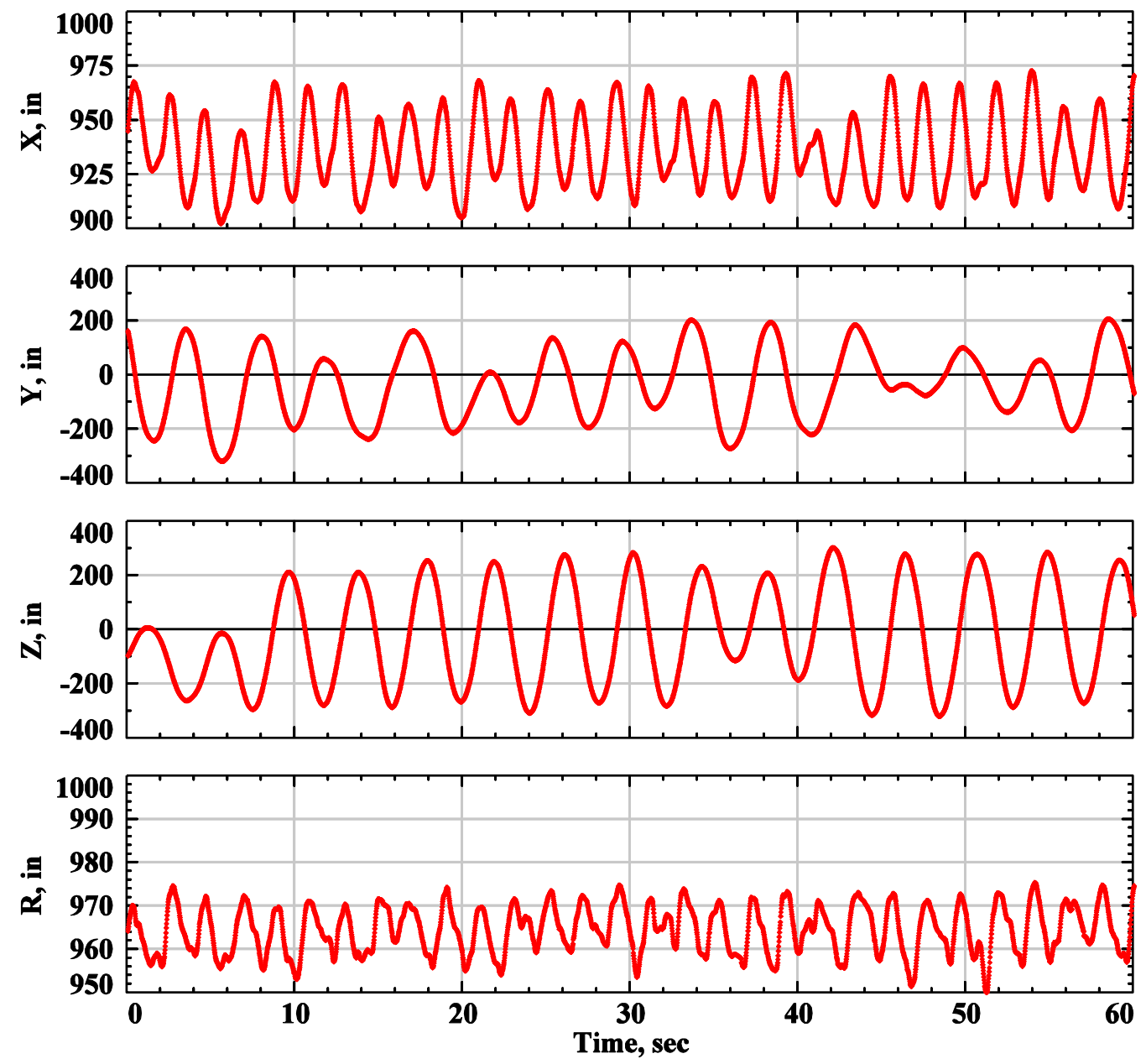

Fig. 10 Typical time-histories of LDSD canopy positions. 

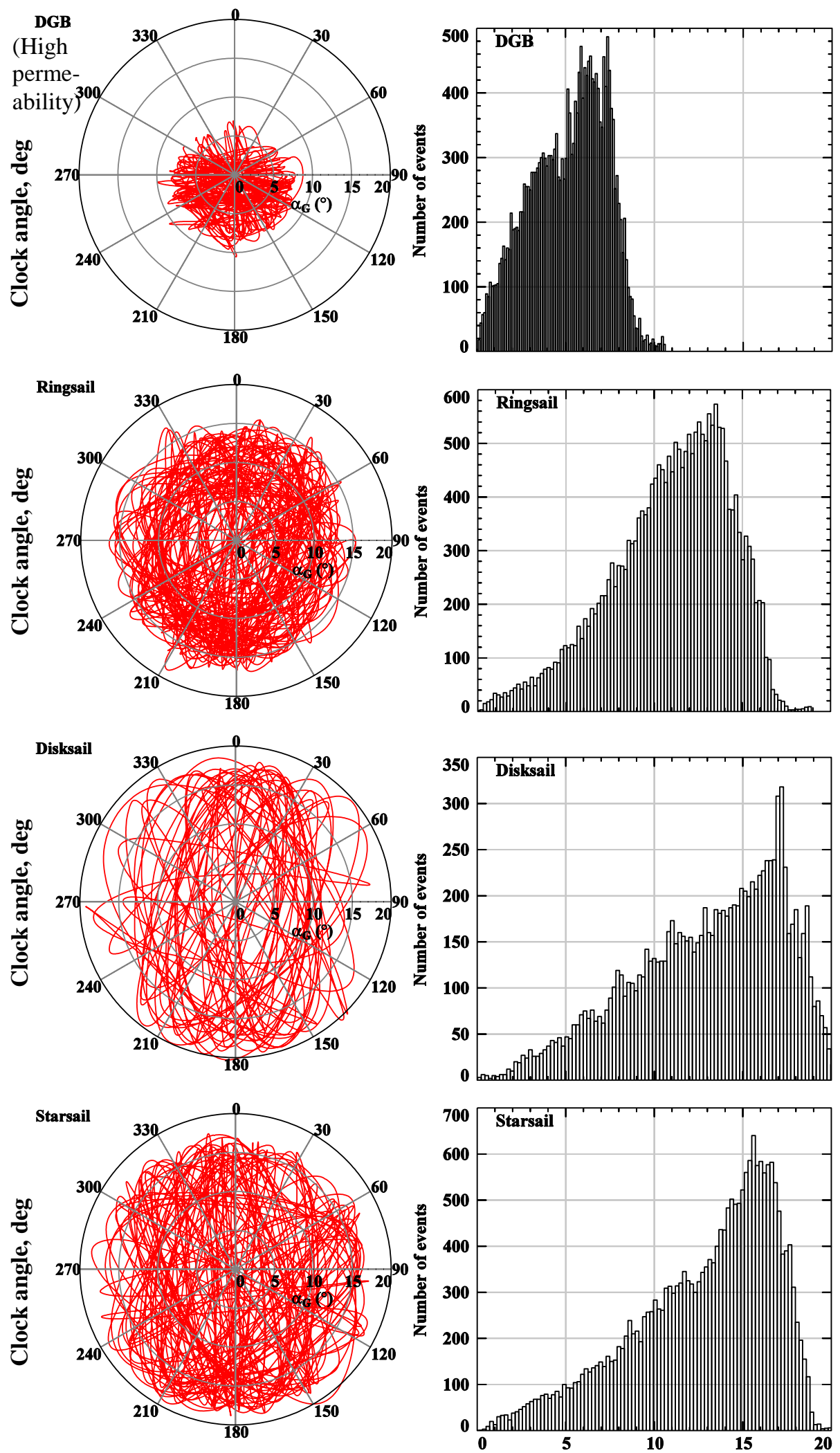

Geometric angle of attack, degrees

Fig. 11 Time traces of clock angle $(\Phi)$ vs geometric angle $\left(\alpha_{G}\right)$ (left) and histograms of $\alpha_{G}($ right). 


\section{Capsule Parachute Assembly System}

The CPAS test configuration was very similar to the LDSD test (Fig. 12). Just as for LDSD, the main concern was how variations on chute design affected the trade-off between drag and stability. The nominal diameters of the CPAS parachutes were slightly larger than for the LDSD chutes; the same strut was used to support the riser; and the parachutes flew at about the same stream-wise position - just beyond the downstream end of the crane position. There were, however, important differences. Most CPAS runs began with a sweep of static angles of attack where the inflated parachute was pulled laterally to one side of the tunnel by a system of three tethers. These angle changes were produced by rotating the turntable and thereby altering the position of the riser attachment point while the position of the vent remained fixed. After data at the last static angle had been collected, the tethers were released and free-flight dynamic data were acquired.

Another difference from the LDSD test was that canopy shape measurements were attempted. These measurements were not required, but were made on a piggy-back, non-interference basis.

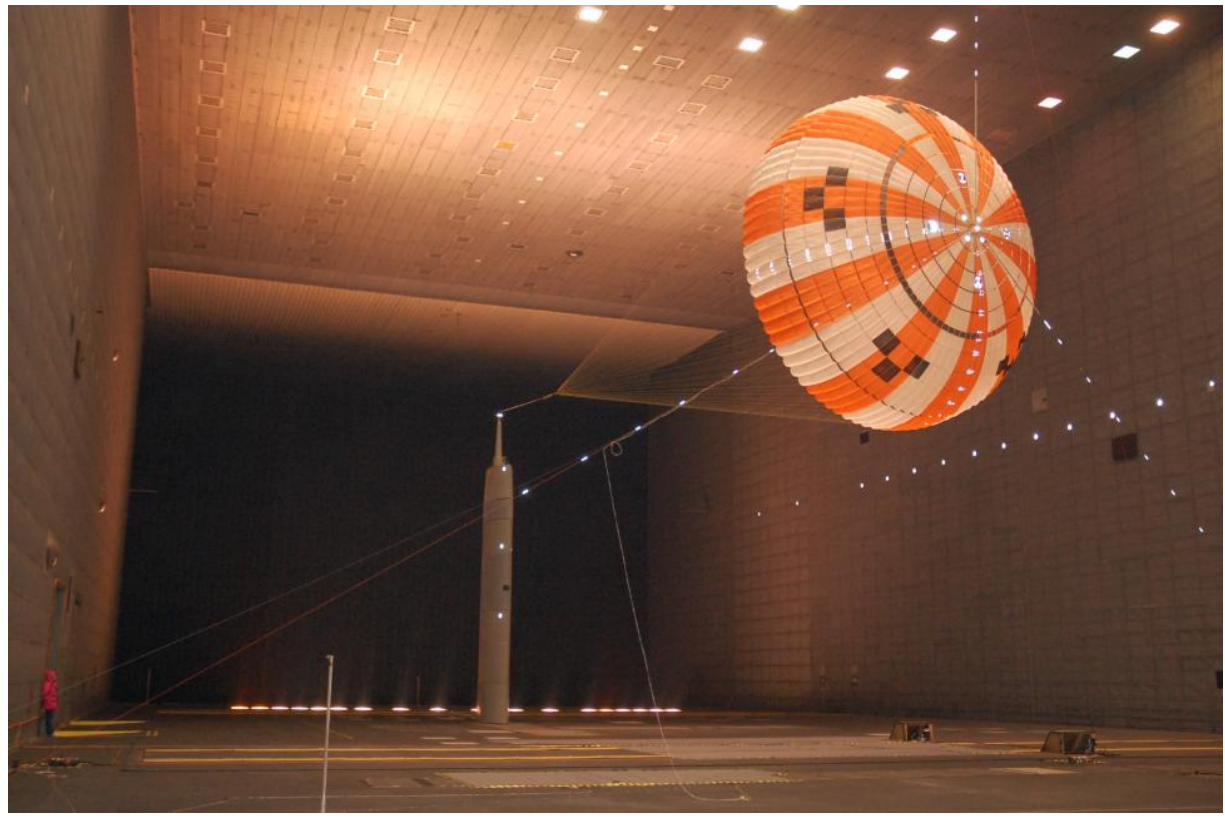

Fig. 12 Test configuration for CPAS showing tethers for static measurements.

\section{A. Test Articles}

All of the CPAS test articles were variations on a Ringsail design. They had 80 gores, were $35 \%$ of full scale, had nominal diameters of $40.8 \mathrm{ft}(12.4 \mathrm{~m})$, and projected diameters of about $28 \mathrm{ft} .(8.5 \mathrm{~m})$. One canopy was a engineering development unit (EDU) that served as a baseline. The main difference between it and other canopies (e.g., "Super Sail") was the magnitude and distribution of geometric porosity. The CPAS test articles were built by Airborne Systems.

Just as for the LDSD test, four retro-reflective and four coded targets were sewn to the rings surrounding the vent. In addition, to allow measuring the longitudinal shape of the canopy, 1/2-in. diameter adhesive retro-reflective targets were applied to each ring from vent to skirt along several gores.

\section{B. Tether System}

For static test points, three tethers attached to the vent pulled the canopy toward the side of the test section. One tether extended down from an opening in the ceiling near centerline; and the other two extended from the vent to anchor points on the floor near each sidewall (Figs. 13,14). All three anchor points were located slightly downstream of the vent to avoid interference between the tethers and the canopy. The two anchor points on the floor could be adjusted in the stream-wise direction. Each tether included a load cell near the attachment point to the vent. Retroreflective targets were applied to the load cells and at regular intervals along each tether. Angle changes were produced by holding the vent at a roughly fixed position and changing the position of the pivot by rotating the turntable. This procedure changed the distance between the vent and the pivot at each angle and thus required a variable-length riser. 
It was observed that the sum of the distances from the vent to the pivot and from the pivot to a point on the floor just upstream of the turntable remained nearly constant over the range of turntable angles needed to produce the desired range of angles of attack. Therefore, a variable-length riser was created by passing the riser over a pulley at the pivot and down to an anchor point on the floor. This arrangement automatically compensated for nearly all of the changing distance from the pivot to the vent as the turntable rotated.

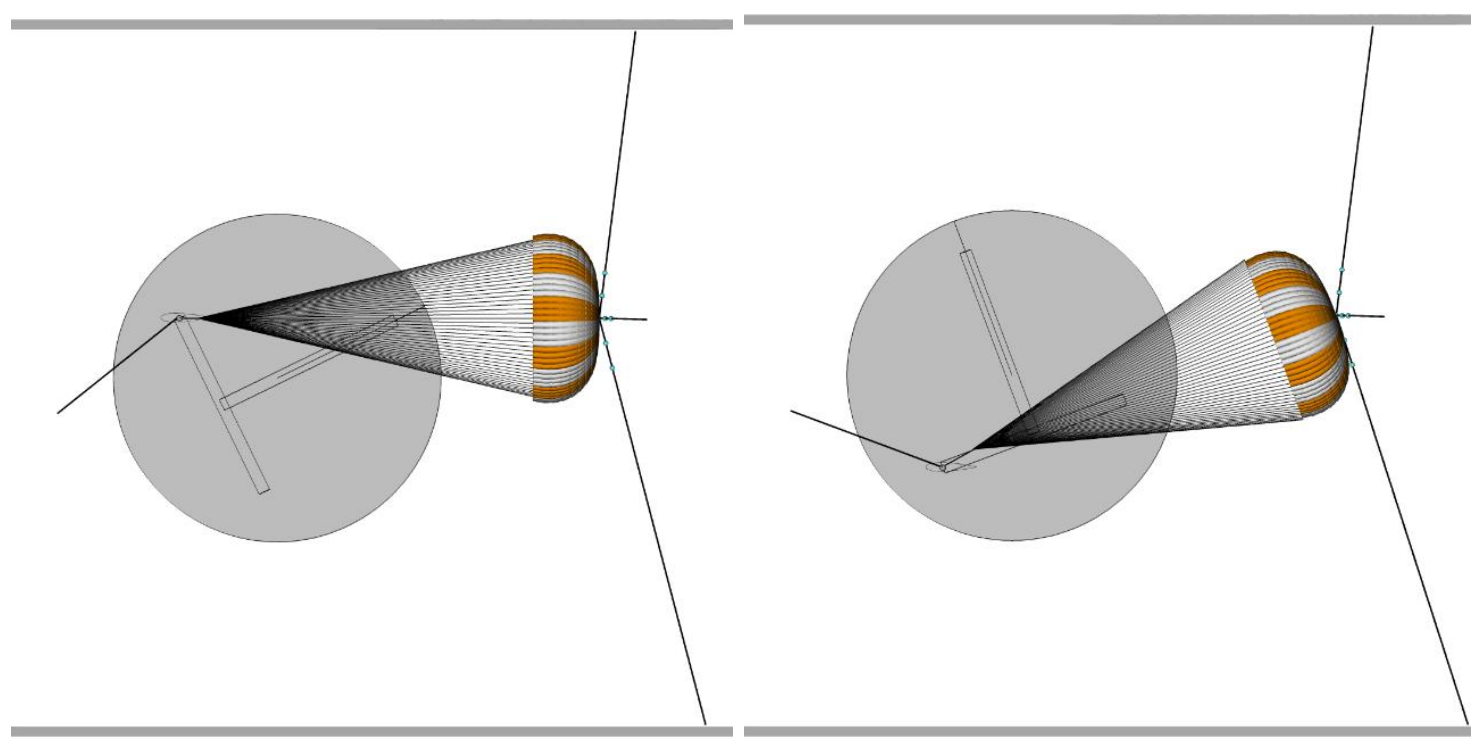

Fig. 13 Top view of CPAS static test configuration showing tethers, turntable, and variable-length riser at $\alpha=$ $0^{\circ}$ (left) and $20^{\circ}$ (right).

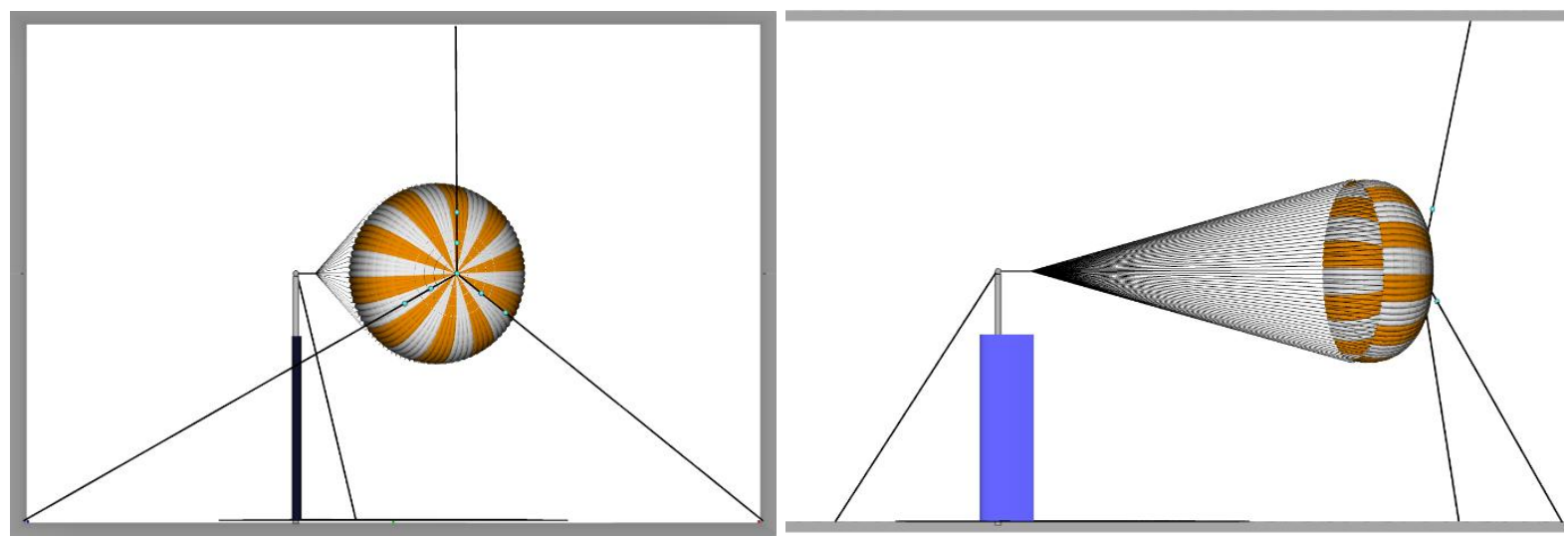

Fig. 14 Rear (left) and side (right) views of CPAS static test configuration at $\alpha=20^{\circ}$.

\section{Cameras and Lamps}

The camera system for the CPAS test was nearly identical to that for LDSD except that the third camera, mounted on the strut for LDSD (and never used), was moved to the floor of the diffuser, where it was placed on tunnel centerline and pointed upstream (Fig. 15). A camera in this position was needed for CPAS because the canopies moved farther from the tunnel centerline than for LDSD; at extreme positions the vent was not visible to either the east or west camera, but it was always visible to the center camera.

Center

To measure the shapes of the canopies, two digital SLR cameras, each with a flash lamp, were placed on the floor of the test section, one just upstream and the other just downstream of the canopies. These cameras were pointed up toward the canopy and were manually triggered to acquire a sequence of ten images. Because of difficulties in timing the trigger so that the gore-shape targets were simultaneously in the fields of view of both cameras photogrammetric 


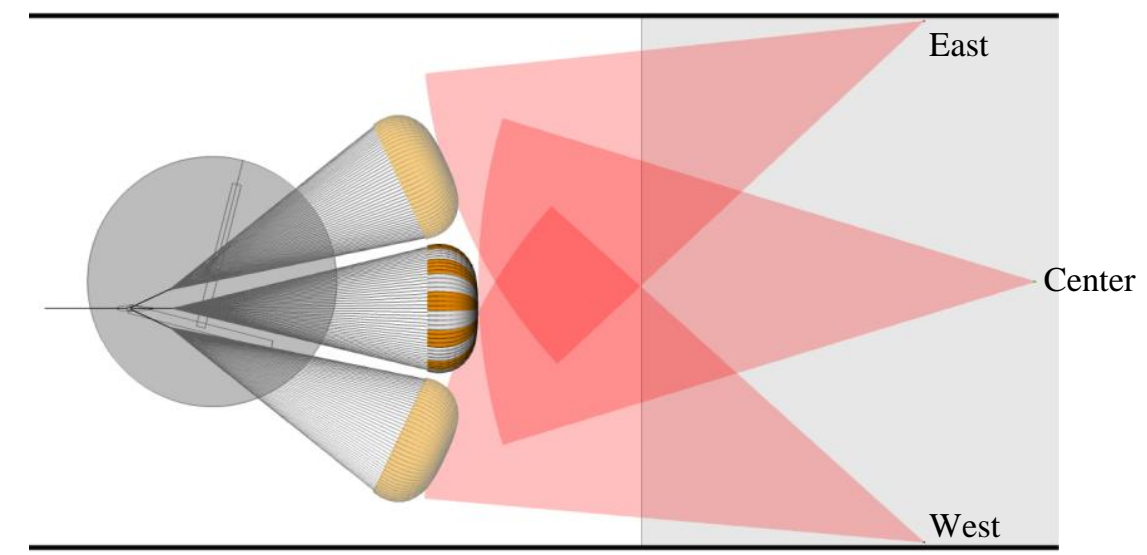

Fig. 15 Top view of CPAS free-flight test configuration showing camera fields of view and canopy at $\alpha= \pm 25^{\circ}$.

measurements were ever extracted from these images. However, measurements of the gore shapes were demonstrated using images from cameras in the diffuser.

The same calibration procedure that was used for LDSD was also used for the CPAS. The entire process-applying targets to the crane and measuring their positions by V-STARS - had to be repeated because the targets for LDSD had long since been removed. The distribution of targets on the crane was improved and targets were placed much higher using a long telescoping pole from the top of the scissors lift. Just as for LDSD, the V-STARS shoot included images of the crane in three lateral positions.

\section{Data Acquisition}

A typical run began with a sequence of static test points over a range of angles of attack between $-5^{\circ}$ and $25^{\circ}$. A final static point was usually acquired at $\alpha_{G}=20^{\circ}$ with the turntable rotated so that the pivot was at the same lateral position as the riser anchor point (Fig. 15). Then the tethers were released and free-flight data were recorded for two minutes, first at $U=20 \mathrm{kts}$, then at $30 \mathrm{kts}$.

\section{E. Data Analysis}

Analysis of the dynamic free-flight data was the same as for LDSD except that the origin of coordinates was different at each position of the strut. The riser attachment point on the strut was marked by a target that appeared in the images from all three cameras, and its position at each test point was computed by photogrammetry.

For each static test point, the pull directions of the tethers at the vent were determined by measuring the position of the vent and one target on each tether nearest the vent (Fig. 16). This allowed the force measured by the load cell in each tether to be resolved into body-axis coordinates.

Gore-shape measurements were made by manually locating the gore-shape targets in images from two cameras and computing the 3D space coordinates of the targets from Eq. 3. These measurements were then rotated into bodyaxis coordinates.

\section{F. Results}

The test included 37 separate runs. Photogrammetry measurements were made at all test points. Sample data are presented that were unique to this test - static measurements and gore-shape measurements - and omit measurements that were also made for LDSD - free-flight data. See Ref. [17] for a complete account of the results from the CPAS test.

Figure 17 presents tether data from static angle-of-attack sweeps for two canopy configurations (EDU and Supersail with 5.5\% porosity). Each "static" measurement is the average of the full 30 seconds of image and load-cell data $(30 \times 60 \mathrm{~Hz}=1800$ instances $)$ acquired at that angle. The load-cell and photogrammetry data were synchronized by means of the strobe that appeared in the photogrammetry images and as a pulse in the DAS. Error bars indicate the standard deviation of each measurement. As expected, the higher porosity of the Super Sail canopy results in less drag than the EDU, but the magnitude of the restorative normal force, and thus the stability, is greater. 

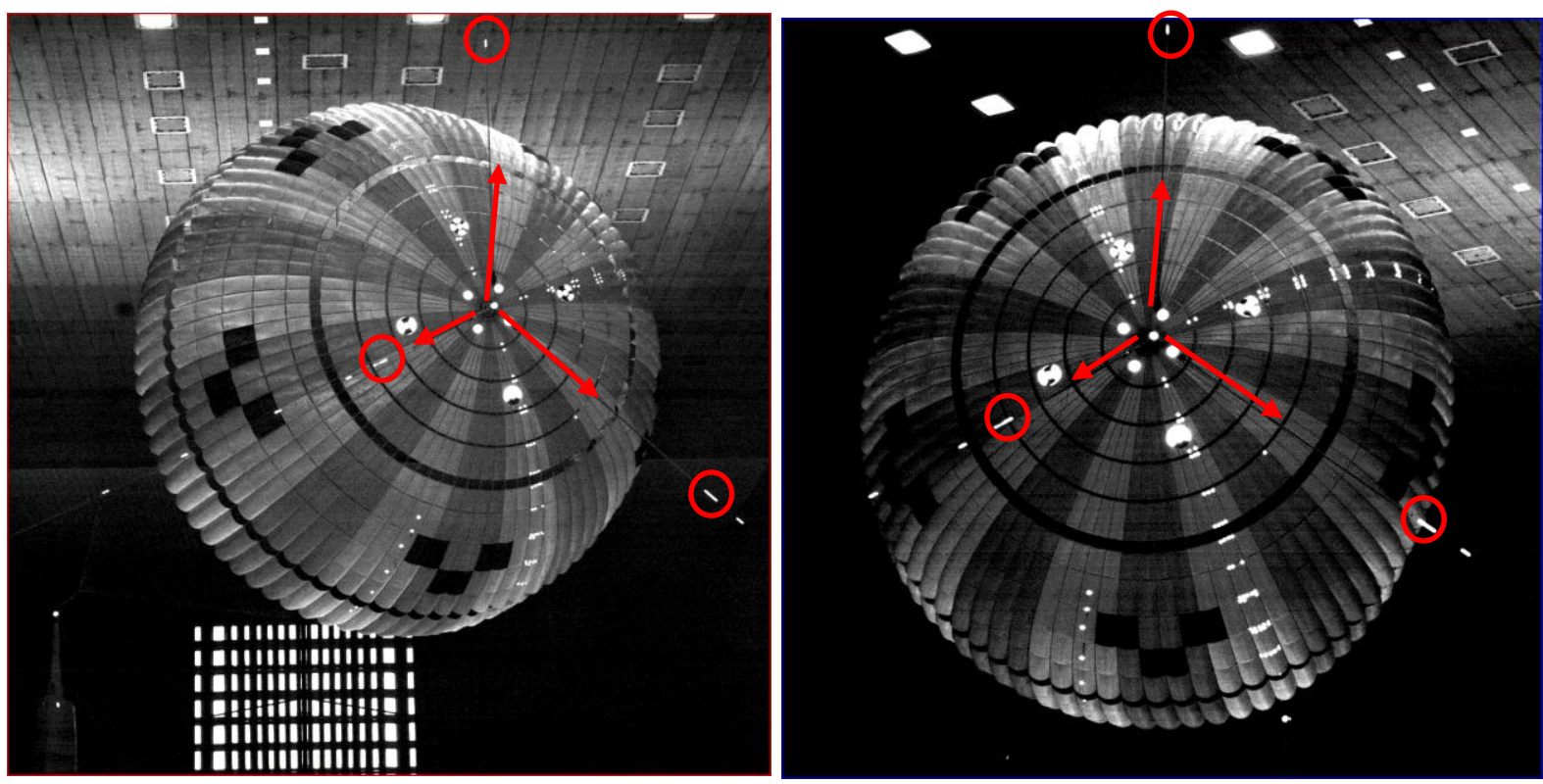

Fig. 16 Enlarged images of CPAS canopy at static test point from center (left) and east (right) cameras showing tether targets (circled). Coded targets and targets to measure gore shapes are also visible.

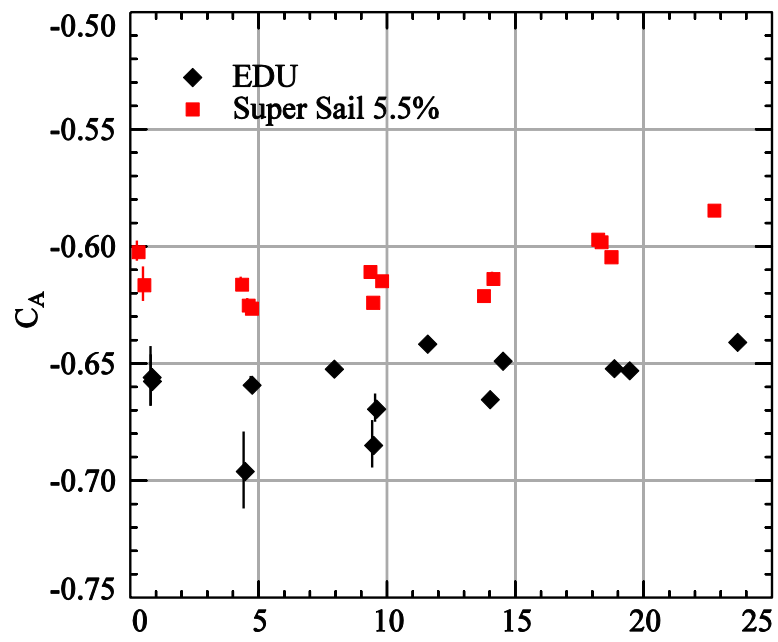

Angle of attack

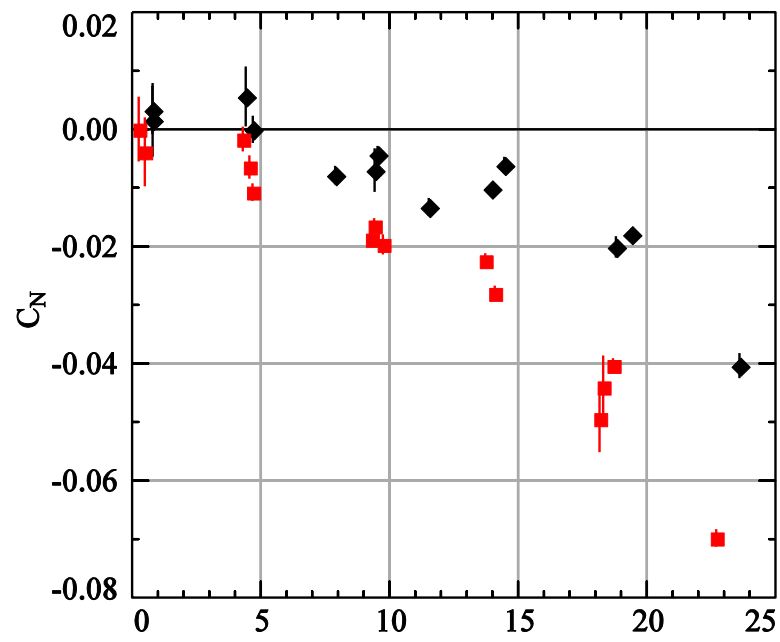

Angle of attack

Fig. 17 CPAS static measurements of axial $\left(C_{A}\right)$ and normal $\left(C_{N}\right)$ force coefficients vs angle of attack for two canopy configurations (courtesy Jessica Powell/JSC, see Ref. 17).

At most static test points, the canopy position and shape remained quite steady. However, at some conditions, the canopy exhibited significant unsteady "breathing" where the vent periodically moved along its axis, towards and away from the pivot. As the vent moved toward the pivot, the inflated diameter increased; and as it moved away, the diameter decreased. This is illustrated for one such unsteady case in Fig. 18. At the top of the figure, images from the west and center cameras have been overlaid by red markers along one gore showing canopy-shape measurement points; the plot at bottom-left shows the distance of the vent from the pivot versus time; and the plot at bottom-right shows the shape of the gore at the three times indicated by the color symbols in the lower-left plot. 

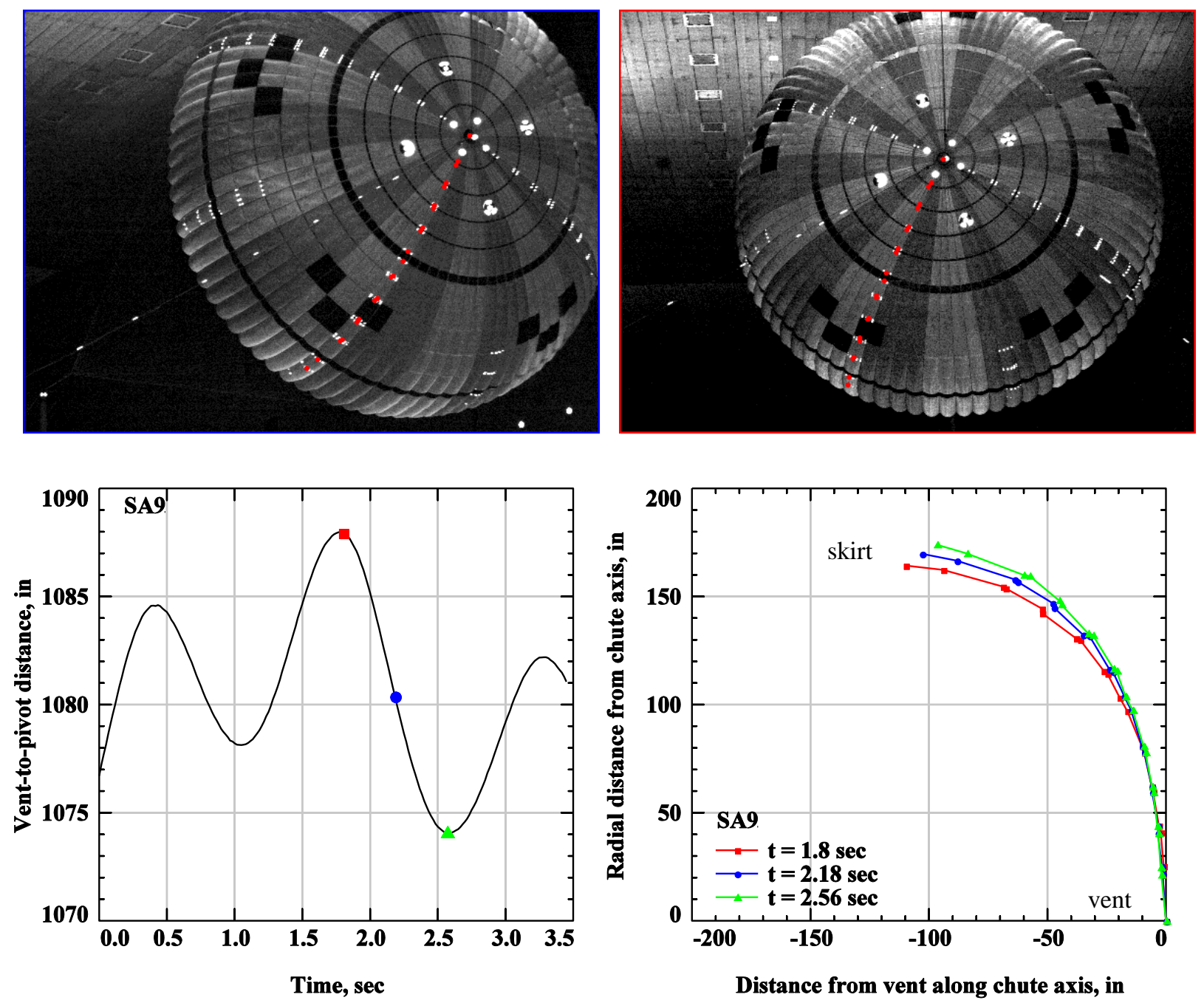

Fig. 18 Images showing gore targets (red) from west (left) and center (right) cameras. Vent-to-pivot distance vs time (lower-left) and gore shape measurements (lower-right) at three instances indicated at lower-left.

\section{InSight}

Each InSight parachute was packed in a bag and fired from a mortar on top of the same strut that was used for LDSD and CPAS. The turntable was rotated to place the strut on the tunnel centerline. There were six canopy deployments in the first entry and four in the second.

\section{A. Test Articles}

All of the canopies (Fig. 18) were essentially the same as the Mars Phoenix parachute except for differences in textiles. They were full-scale DGB parachutes with 40 gores and $D_{0}=38.7 \mathrm{ft}(11.8 \mathrm{~m})$ - the same design as the reference DGB parachutes in the LDSD test. In the first entry, canopies for all six deployments were packed in their bags using a "z fold." In the second entry, one canopy was packed with the $z$ fold, and three others using a "pseudoaccordion" fold. Since photogrammetry was not planned for the first test, there were no targets on the bags or canopies. For the second entry, 2-in diameter retro-reflective targets were applied to the sides and end of the roughly cylindrical 


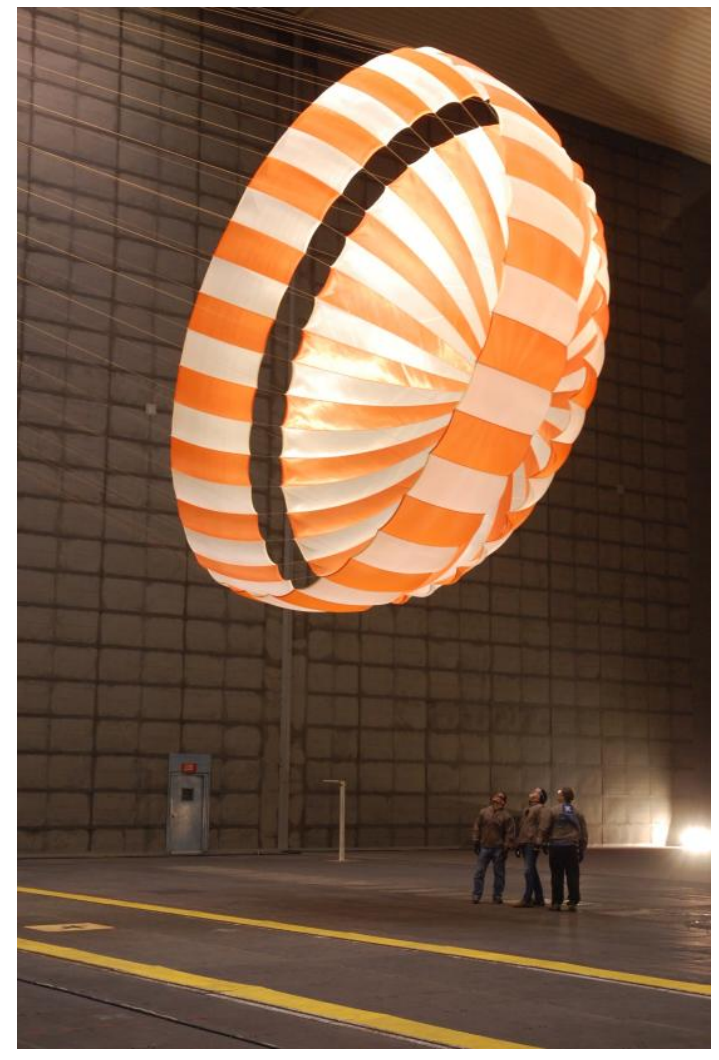

Fig. 19 InSight DGB parachute.

bag. Once inflated, the parachutes flew in the test section at about the same stream-wise position as the LDSD and CPAS chutes-just downstream of the crane position. All of the canopies were built by Pioneer Aerospace.

\section{B. Cameras and Lamps}

The first InSight entry occurred immediately after the CPAS test, and the calibrated CPAS cameras (Dalsa $4 \mathrm{M} 60 \mathrm{~s})$ and the halogen lamps were still in place. No recalibration of the cameras was necessary. The photogrammetry measurements were made on a "piggyback," non-interference basis.

For the second InSight entry, the Dalsa 4M60s were replaced by three high-speed Phantom v641 cameras (2560 x 1600 pixels, $750 \mathrm{~Hz}$ ). Two cameras were mounted in the diffuser at the same east and west positions as for CPAS (Fig. 14). They were pointed and lenses were chosen to provide the best images during the time interval between the end of "line stretch," when the suspension lines were fully extended and were beginning to pull the canopy from the bag, and the end of "bag strip," when the canopy was fully out of the bag and just beginning to inflate. The third camera viewed the canopies from the side, but it was not used for photogrammetry. Illumination was provided by six banks of theater lamps.

For the second InSight entry, the two downstream, high-speed cameras were calibrated using images of the crane. Time and budget constraints did not allow another V-STARs shoot, so no targets were applied to the crane. Instead data from CPAS (images and calibrations) were used to compute the spatial coordinates of permanent features on the crane that appeared in the InSight calibration images. These coordinates were then used with the image-plane coordinates of the same features in the InSight images to compute the DLTs of the InSight cameras. The range and number of the calibration points was expanded by positioning the crane at five lateral positions and acquiring images with the InSight cameras at each position. The lateral displacement of the crane at each position was measured with a tape measure. By this procedure, the time and effort required to calibrate the cameras was drastically reduced.

\section{Data Acquisition}

The parachutes were launched after the desired free-stream condition was established. For the first entry, the cameras were manually commanded to begin recording several seconds before the parachutes were launched, and they continued recording until several seconds after the parachutes had inflated. For the second entry, the cameras were triggered automatically at a pre-determined delay $(0.5 \mathrm{sec})$ after the mortar was fired. A delay was necessary because the camera buffers were not large enough to store images from mortar firing through the end of bag strip. Therefore, the delay was chosen so that data acquisition would begin just before the interval of interest: from the end of line stretch to the end of bag strip. The cameras continued to acquire images until the on-camera data buffers were fullabout 1.7 seconds. These high-speed recordings ended about when the canopies became fully inflated.

\section{Results}

The dynamic pressure was between 16 and 24 psf for the six deployments of the first entry. The first two deployments of the second entry were at $q=17 \mathrm{psf}$; the last two were at $q=12 \mathrm{psf}$.

Figure 20 shows two images from two mortar firings, one from the first entry (left) and the other from the second (right). The upper images in Fig. 20 show the end of line stretch, and the lower images show the end of bag strip. The images from the first entry have a significantly wider field of view and include the strut, mortar, and riser attachment point.

Figure 21 (a) shows the stream-wise positions of the bag versus time relative to the end of line stretch for all launches; and Fig. 21 (b) shows the vertical position versus stream-wise position, also relative to the end of line stretch. 

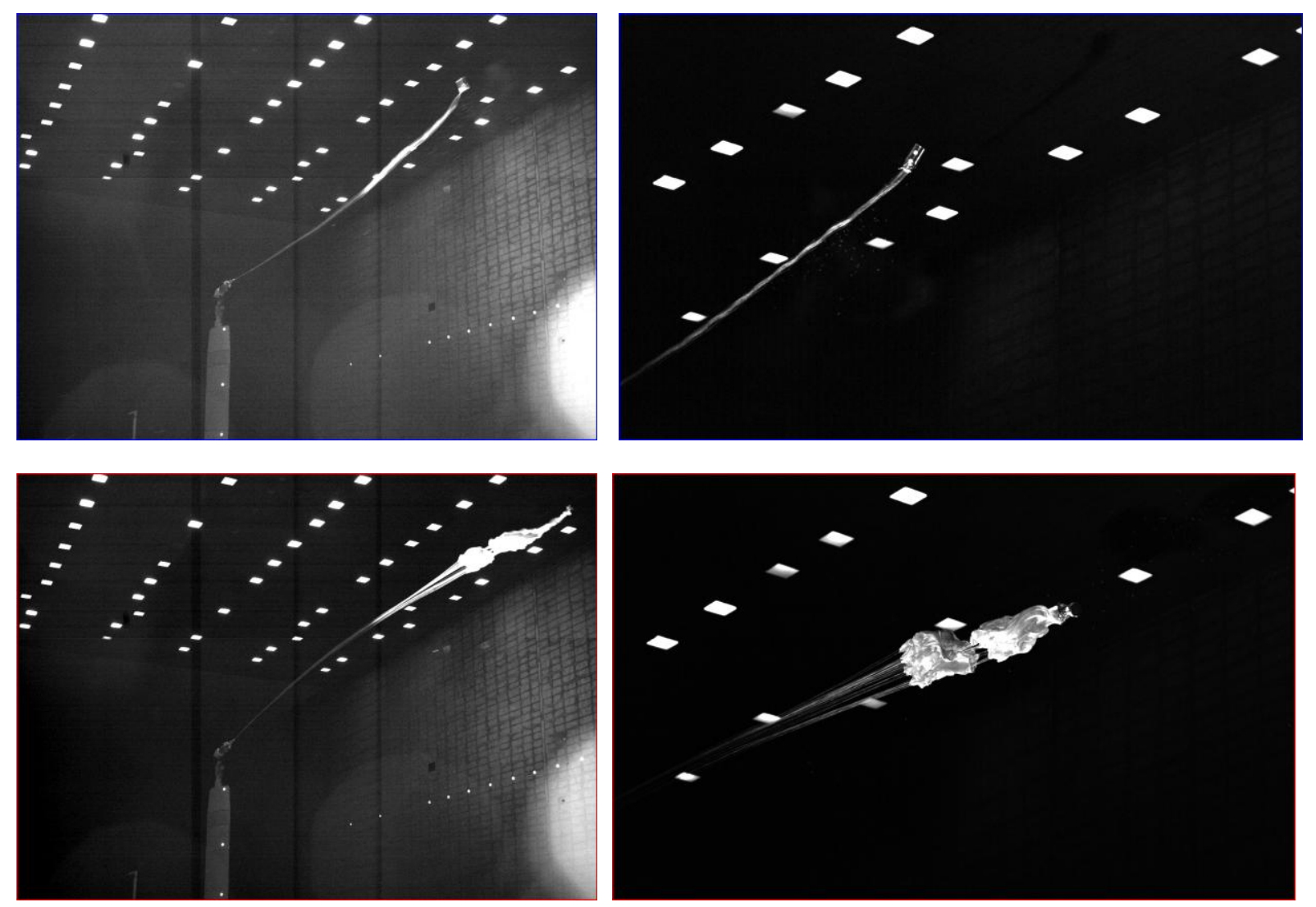

Fig. 20. Images of mortar deployments from west camera from first (left) and second (right) InSight entries. Top: end of line stretch; bottom end of bag strip.
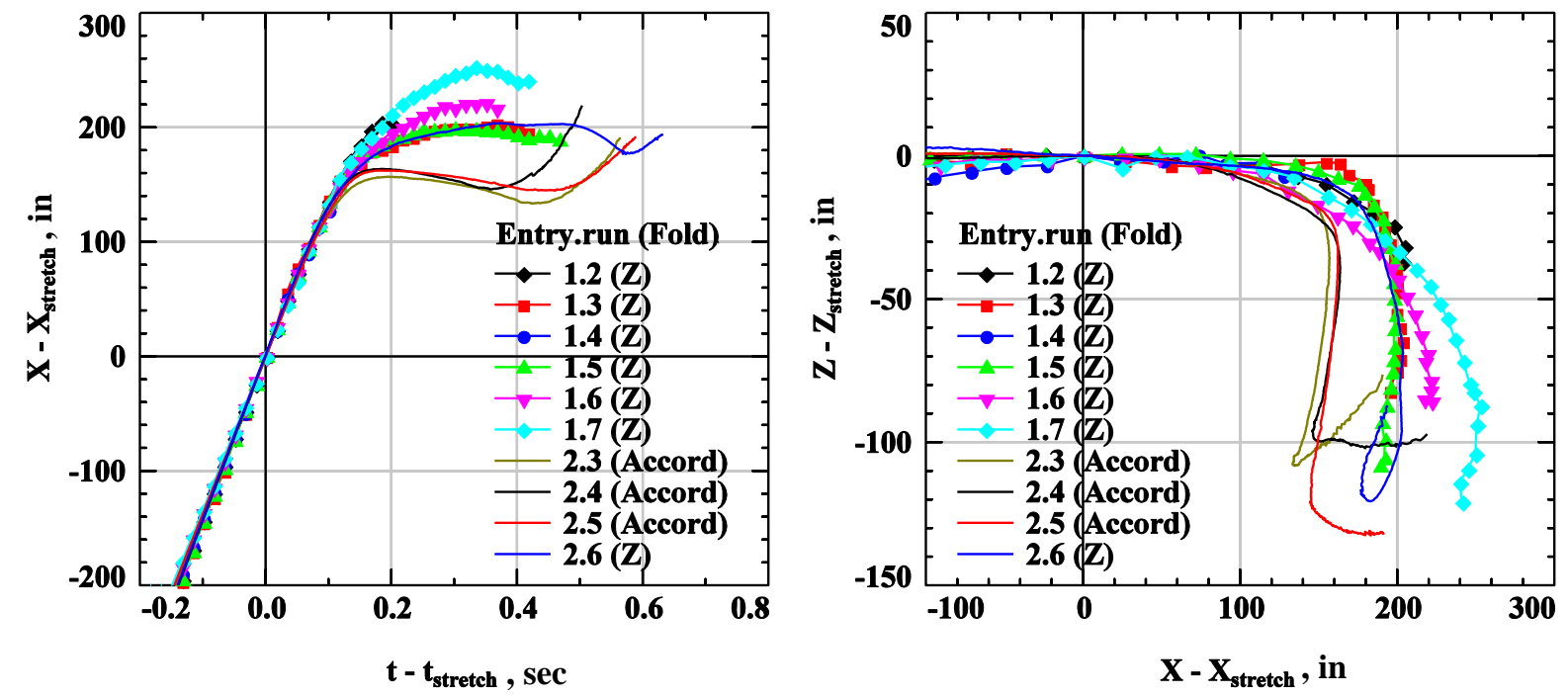

Fig. 21 The effects of packing method ("z" vs "pseudo-accordion" folds) on bag strip: mortar deployments of InSight parachutes during first (symbols) and second (lines only) entries.

The data show that both the distance downstream and the height of the bag relative to the end of line stretch were less for the three pseudo-accordion-fold deployments than for the $\mathrm{z}$-fold deployments. This conclusion is supported by the good agreement between the single $\mathrm{z}$-fold deployment from the second entry and the four z-fold deployments from the first, which occurred nine months earlier. It should be noted, however, that presenting the data in this way requires 
identifying the frame corresponding to the end of line stretch for each deployment. Because of the lower frame rate $(60 \mathrm{hz})$ of the images from the first entry, the uncertainty in estimating the time and position of the end of line stretch was much larger than for second entry. Another observation from the second entry was that there was little or no bag rotation or canopy twisting for the pseudo-accordion-fold deployments, while twisting of the z-fold deployment was less pronounced than during the first entry. The lower twisting of the z-fold canopy in the second entry is attributed to the lower dynamic pressure of the test condition.

\section{Mars 2020}

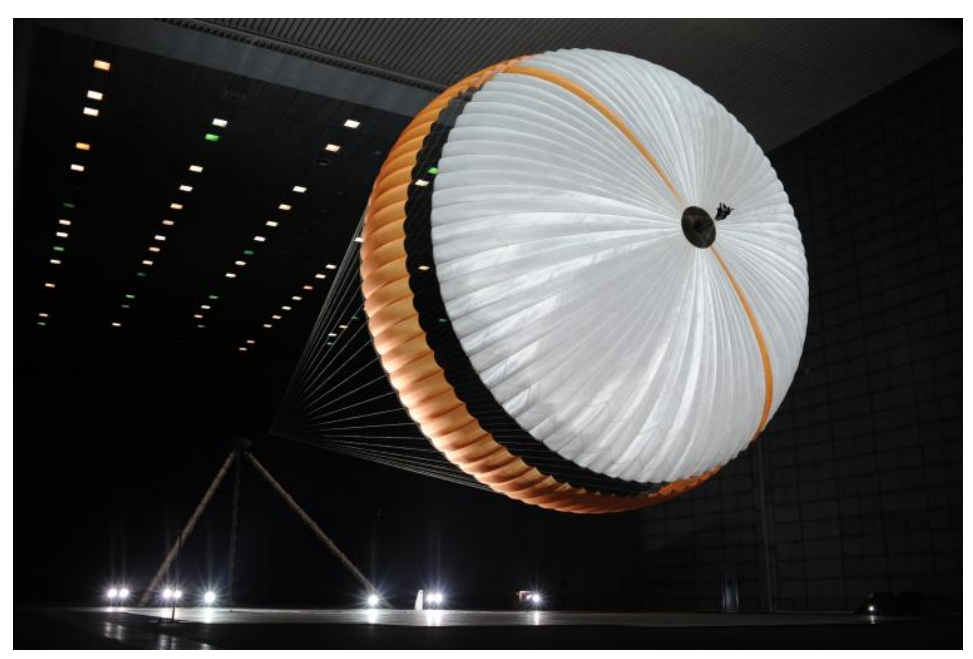

Fig. 22 Inflated Mars 2020 parachute after mortar deployment (photo courtesy JPL).
The Mars 2020 test (Fig. 22) was very different from the LDSD, CPAS, and InSight tests mostly because the parachutes were much larger and flew further downstream. In addition, because the axial loads were much greater, Mars 2020 required a different model support. Mars 2020 was similar to InSight in that both tests included mortar deployments; however, unlike InSight, the Mars 2020 test also included sleeve deployments. Finally, the imaging system for Mars 2020 was significantly different: 13 high-speed cameras distributed in the test section and diffuser. No photogrammetry was planned, so the cameras were not calibrated. The camera calibrations and photogrammetry measurements were "bootstrapped" from the image database after the test was over.

\section{A. Test Articles}

Except for materials, the Mars 2020 parachutes were identical to the parachute used for MSL. They were DGB parachutes with 80 gores, nominal diameters $\left(D_{0}\right)$ of $70.5 \mathrm{ft},(21.5 \mathrm{~m})$, and projected diameters of about $0.72 \times D_{0}=$ $50.8 \mathrm{ft}$. Parachutes from two vendors were tested: Pioneer Aerospace and Airborne Systems.

The model-support system for Mars 2020 was the same "tripod" that was used for the MSL tests in 2009 [18]. The mortar and riser attachment point were at the top of a $40-\mathrm{ft}$ tall vertical post mounted on the tunnel centerline just upstream of the turntable. The post was braced by two diagonal legs which extended downstream to port and starboard attachment points in the floor of the test section just outboard of the turntable (Fig. 23).

\section{B. Sleeve Deployment}

Sleeve deployment is an economical alternative to mortar deployment that results in comparable peak inflation loads without the safety complications associated with the use of mortars. With sleeve deployment, the canopy and suspension lines are stretched along the tunnel axis between the attachment point at the top of the tripod and a fixture attached to turning vanes at the downstream end of the diffuser. The canopy is cradled in a long, narrow hammocklike sleeve the sides of which are held together at regular intervals by closure pins that are tensioned by bungee cords. The configuration is stabilized by two tethers that are attached to the upstream end of the sleeve and descend to the floor of the test section, one to port and the other to starboard. Deployment begins when the tension line between the downstream end of the sleeve and the turning vane is cut at the sleeve attachment point. As tension on the sleeve is released, the tension line pulls a ripcord that opens the closure pins, beginning upstream and working downstream, and the sleeve falls away. Once the sleeve is clear of the canopy, the configuration is similar to that of a mortardeployed parachute at the end of bag strip.

\section{Cameras and Lamps}

Thirteen high-speed cameras were deployed by imaging teams from JPL and Ames. All of the cameras were mounted on the floor of the wind tunnel except for one of the Ames cameras, which was mounted at a window in the 
ceiling approximately on centerline and near the downstream end of the test section. The cameras were placed and pointed to provide optimal views from many directions of the bag-strip and canopy inflation segments of the deployments, which occurred when the canopies were in the diffuser.

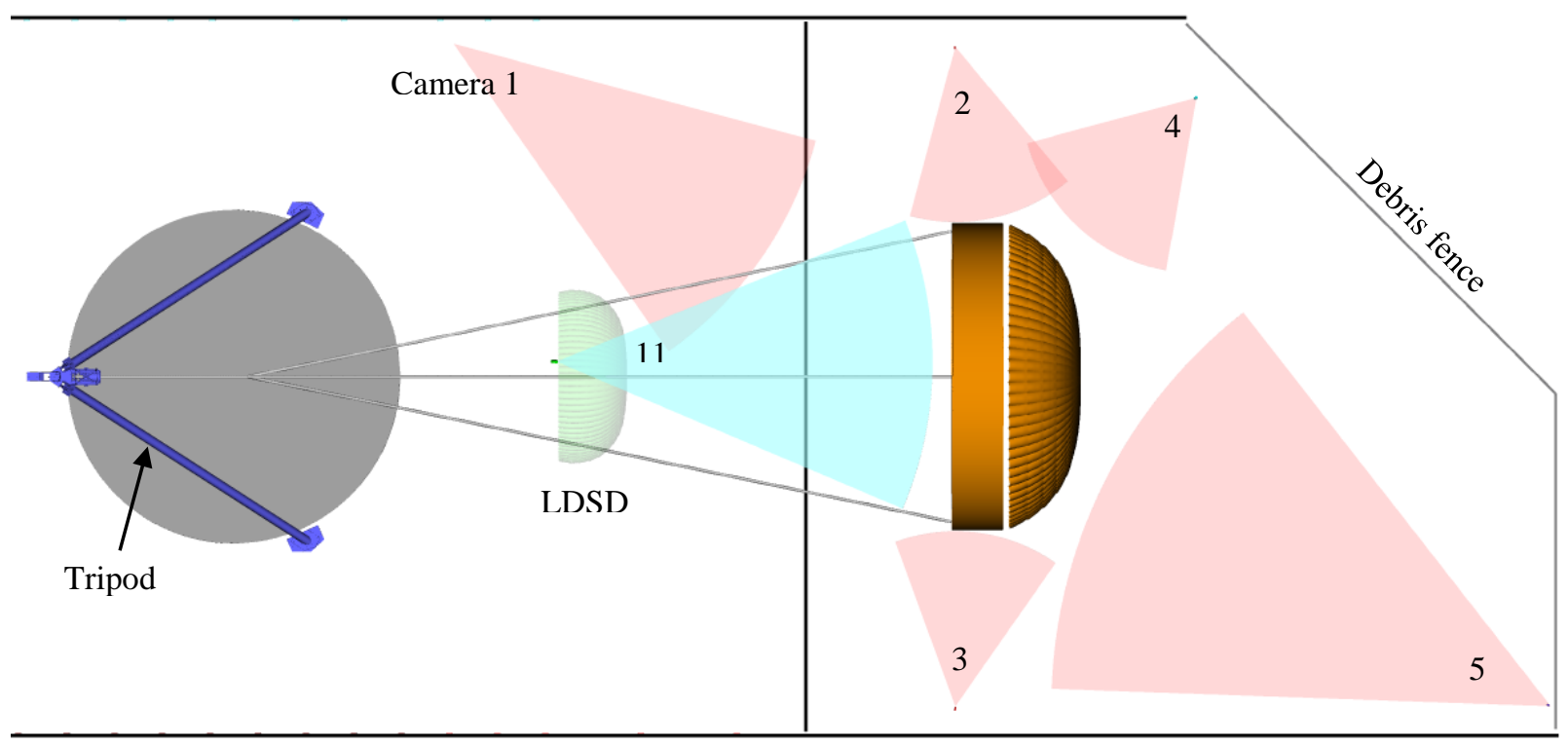

Fig. 23 Top view of Mars 2020 test configuration showing fields of view of Ames cameras (red for floor; cyan for ceiling). The LDSD parachute (green) is included for comparison of the canopy position and size.

Figure 23 is a schematic showing the placement of the six Ames cameras. Five of these camera (Cameras 1-5) were mounted on the floor and were IDT OS-V3-4K ( $3840 \times 2400$ pixels) that recorded images at 250 frames per second for 12.7 seconds. Images were recorded in raw format to removable solid-state memory devices. The storage devices were removed from the cameras and images were downloaded to the host computer and converted to TIFF format after each run. The sixth Ames camera (designated "11" among all 13 cameras) was mounted in the ceiling and was a Phantom V641 (2560 x 1600 pixels) that recorded images at 100 frames per second for 12.8 seconds. Images from the Phantom camera were quickly downloaded after each run across a 10 Gigabit Ethernet link. For mortar deployments, all of the cameras were simultaneously triggered by the same signal that also fired the mortar; for sleeve deployments, the cameras were triggered just before the canopies were deployed. All of the floor-mounted cameras were shielded from the airflow (up to $85 \mathrm{mph}$ ) by shrouds built from plywood. Shrouds for the most downstream cameras, which pointed upstream, were fitted with plexiglass windows.

A local theatrical lighting company installed color-balanced, flicker-free, high-intensity lamps to illuminate the canopies as they inflated. Two ARRI M90 $(9 \mathrm{~kW})$ and eight ARRI M40 (4kW) lamps were placed on the floor along a line stretching across the test section just downstream of the turntable and upstream of the diffuser. The lamps were pointed to provide even illumination in the diffuser. The lamp heads were shielded from the air flow by plywood shrouds. Ballasts for the lamps were placed in the balance house, below the turntable and on top of the $\mathrm{T}$ frame.

A flash-lamp was triggered $11.5 \mathrm{sec}$ after each deployment was initiated. The extra illumination from this lamp appeared in one image from each camera, and the trigger signal was recorded by the tunnel data system.

\section{Cameras Calibration}

No targets were available to calibrate the cameras for Mars 2020. Therefore, the cameras were calibrated using features on the walls of the wind tunnel that appeared in the images and whose spatial coordinates we could estimate. In particular, the sidewalls of both the diffuser and test section were covered by acoustic panels that appear as a rectangular grid in the images. The space coordinates of the nodes of this grid were estimated to within about \pm 1 inch using a tape measure. Likewise, protective panels on the floor of the diffuser provided a grid that could be used for 


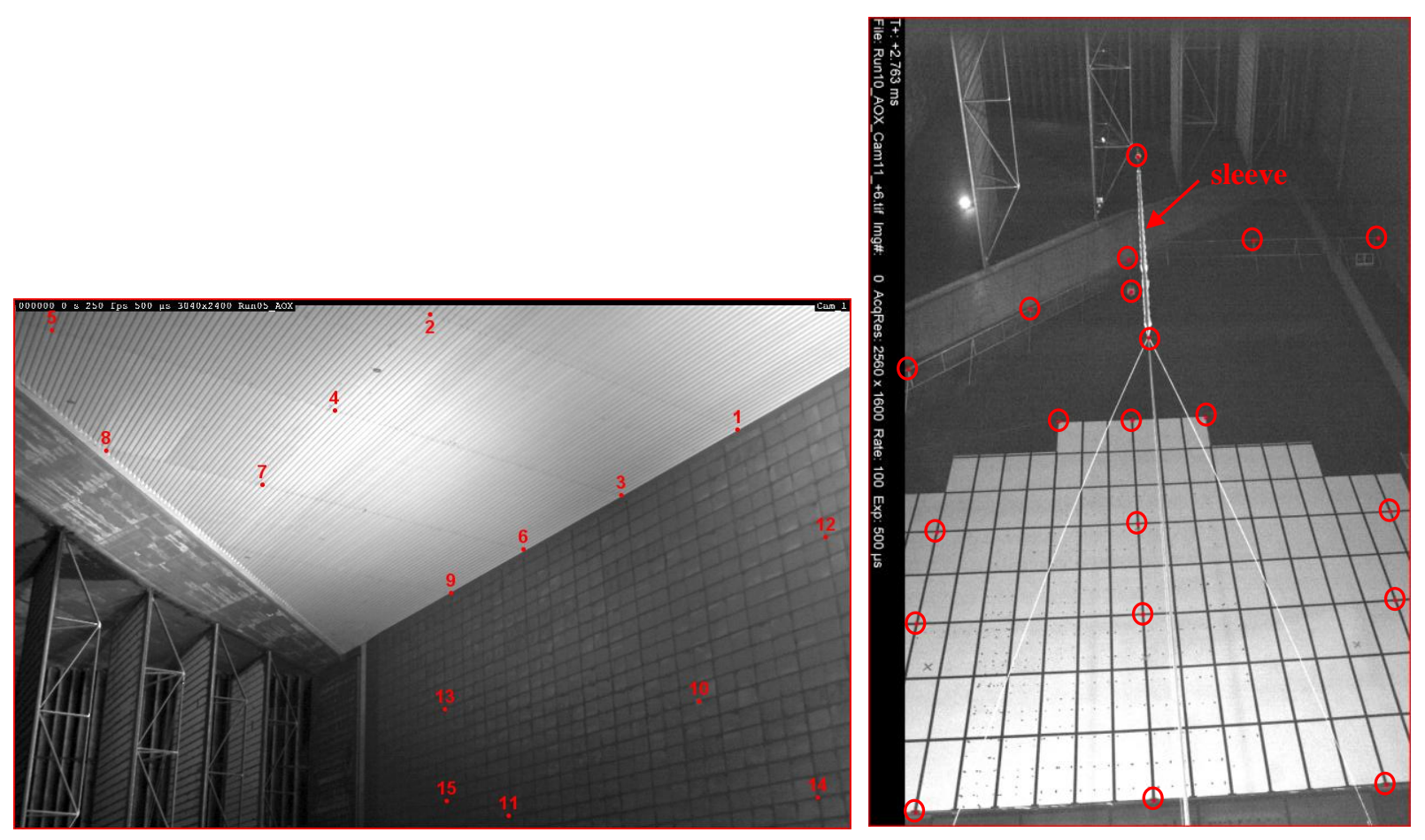

Fig. 24 Calibration targets in images from Cameras 1 (left) and 11 (right).

calibration. Finally, the ceiling of the diffuser included regular features-stream-wise corrugations and lateral seams - whose spatial coordinates we could estimate.

Views from all the floor-mounted Ames cameras included features on both the ceiling and one sidewall, which satisfied the requirement that all of the calibration points not lie in the same plane. The view from the ceiling-mounted camera (Camera 11), however, included only features on the floor. At the beginnings of sleeve-deployment runs, the upstream and downstream ends of the sleeve, which stretched along the tunnel centerline, were easily identifiable features that were visible in the images of all cameras. Therefore, the floor-mounted cameras, which had been calibrated using features on the walls and ceiling, were used to compute the space coordinates of these sleeve features. Then, the sleeve features were included as out-of-plane points for calibrating the ceiling-mounted camera.

The image-plane coordinates of all points used in the calibrations were established manually by "point and click" in the image display. Figure 24 shows images from Cameras 1 and 11 in which features used for calibration are indicated.

\section{E. Data Analysis}

Points of interest on the canopies were located in the images manually by point and click. Except for the vent, which was a unique feature, the correspondence of points in the images from different cameras was not obvious. Errors in correspondence were detected by substituting the computed space coordinates of a measurement point into Eq. 1 and, for each camera, comparing the resulting image-plane coordinates of the point to the observed coordinates. This "re-projection error" was smallest when the correspondence was correct.

All of the results presented here are based on images from floor-mounted Camera 1 and ceiling-mounted Camera 11. Both cameras had good views of the inside of the canopy from upstream. Images from these cameras, however, were of difference sizes ( 3840 x 2400 pixels for Camera 1 vs 2560 x 1600 pixels for Camera 11) and were acquired at different frequencies $(250 \mathrm{~Hz}$ for Camera $1 \mathrm{vs} 100 \mathrm{~Hz}$ for Camera 11). The in-house software had the flexibility to accommodate these differences. Every fifth image from Camera 1 was paired with every second image from Camera 11.

\section{F. Results}

There were six parachute deployments: the first three were mortar deployments and the second three were sleeve deployments. The first mortar deployment was a shake-down run at low dynamic pressure ( $q=6 \mathrm{psf}$ ) using a slightly 
over-size canopy ( $D_{0}=75.4$ vs $68.9 \mathrm{ft}$ ). The two subsequent mortar deployments were at a dynamic pressure ( $q=16.3$ psf) expected to produce peak inflation loads of more than $81,000 \mathrm{lbs}$. The three sleeve deployments were at slightly higher dynamic pressure $(q=16.9 \mathrm{psf})$.
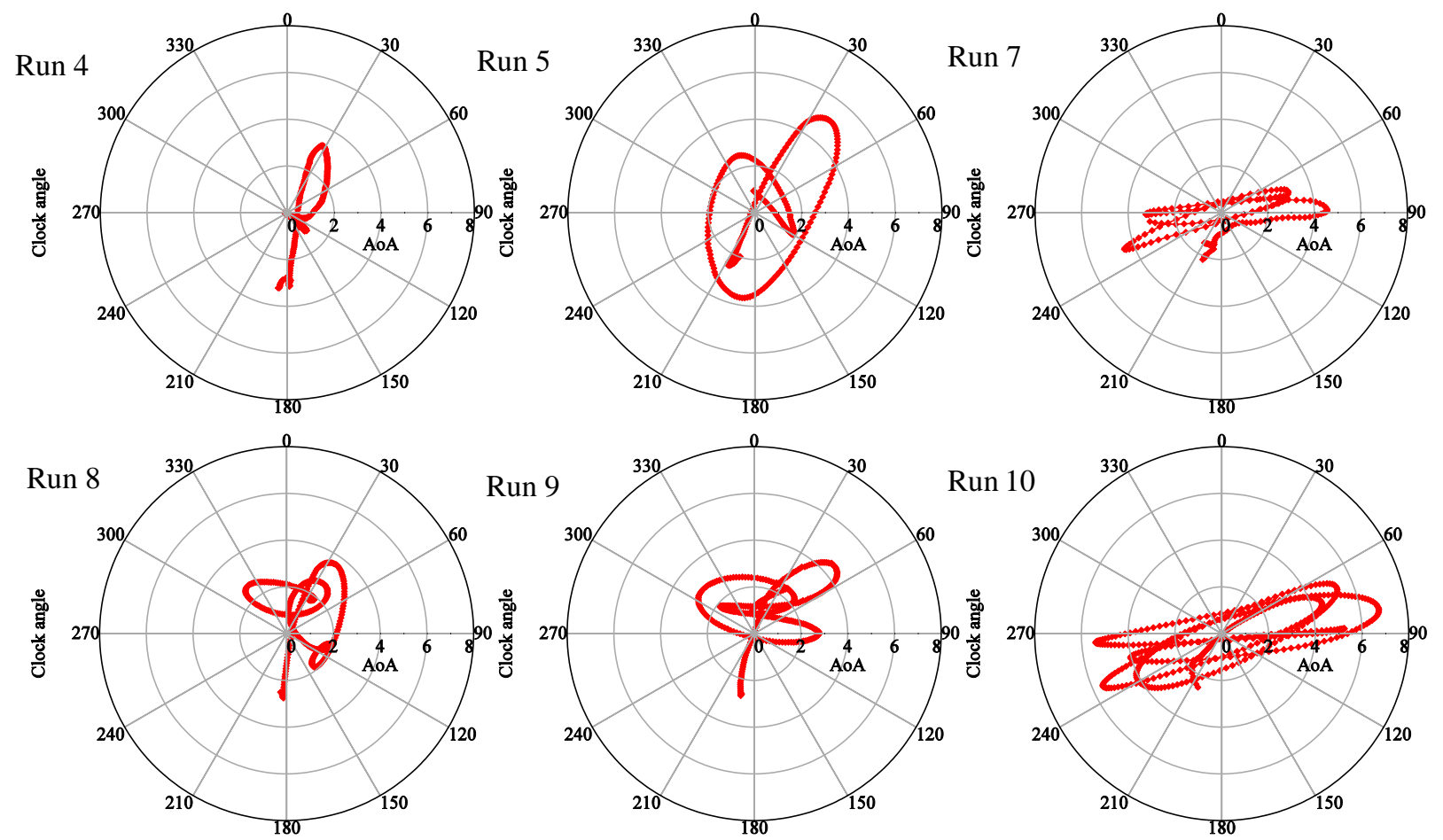

Fig. 25 Time traces of clock angle versus $\alpha_{G}$ of inflated Mars 2020 parachutes. Top row: mortar deployments; bottom row: sleeve deployments.

Figure 25 compares time traces of $\Phi$ versus $\alpha_{G}$ for all six deployments. The data are limited to only 12.7 secs after deployment and thus present a much shorter record than corresponding data for LDSD (Fig. 11). The maximum geometric angle of attack $\left(\alpha_{G}\right)$ was larger for run 10 (the accident run) than for any of the earlier runs, and the pendulum motion was mostly side-to-side. Note that the accident was tunnel-related and did not involve a parachute failure.

Figure 26 shows images from Cameras 1 and 11 of the inflated canopy during the accident run at $t=11.9 \mathrm{sec}$. The images include an overlay of red markers along the circumference of the skirt at the attachment point of each of the 80 suspension lines. The space coordinates of these points in the Y-Z plane are shown in Fig. 27 (a). The measurements have been fit by a circle that indicates an inflated diameter $D_{p}=47.0 \mathrm{ft}=0.66 \times D_{0}$. Figure 27 (b) shows the longitudinal shape of the gore indicated by the cyan markers in Fig. 26.

Figure 28 shows the inflation of the skirt during the two mortar deployments at $q=16.3$ psf. Position measurements in the $Y$-Z plane are shown at time intervals of 0.16 seconds. The most obvious difference between the deployments is the number of lobes as the chute was inflating: three for Run 5 vs four for Run 7. The reason for this difference is unknown. In addition, the chute in Run 5 inflated more rapidly than that in Run 7. This is evident in Fig. 29, where the frontal area of the skirt is shown versus time for both deployments. In both cases, the peak axial load (measured by load cells) occurred at the end of a rapid rise in frontal area but before the canopy had reached its maximum frontal area.

\section{Uncertainties}

The measurement uncertainties were least for the LDSD and CPAS tests, where the camera calibrations were based on targets whose spatial positions had been precisely measured by V-STARS and the canopies were tracked by clearly defined, retro-reflective targets. The measurement uncertainty was slightly different at each instance because of the changing geometry. For a typical position of the canopy and a random uncertainty of one pixel in locating the targets on the canopy, the corresponding uncertainties in the computed 3D coordinates of the target were about $\Delta X=0.5$ in., $\Delta Y=0.25$ in., and $\Delta Z=0.25 \mathrm{in}$. As expected, the uncertainty was largest in the direction $X$ toward the camera baseline. To first order, the spatial uncertainties scale linearly with the random image-plane uncertainty. For the InSight test, 

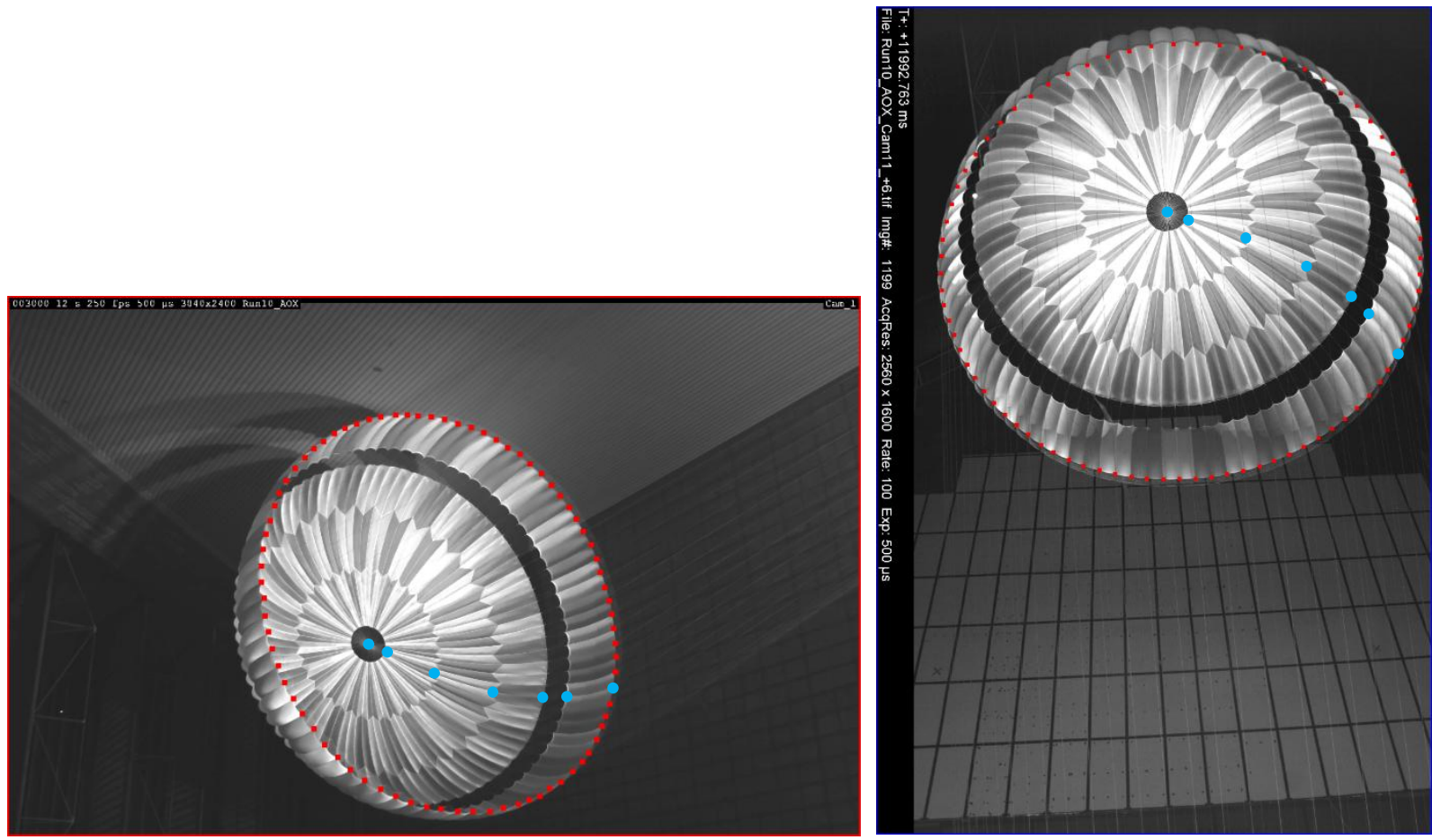

Fig. 26 Images from Cameras 1 (left) and 11 (right) 11.9 sec after sleeve deployment showing targets used to compute skirt shape (red) and gore shape (cyan).
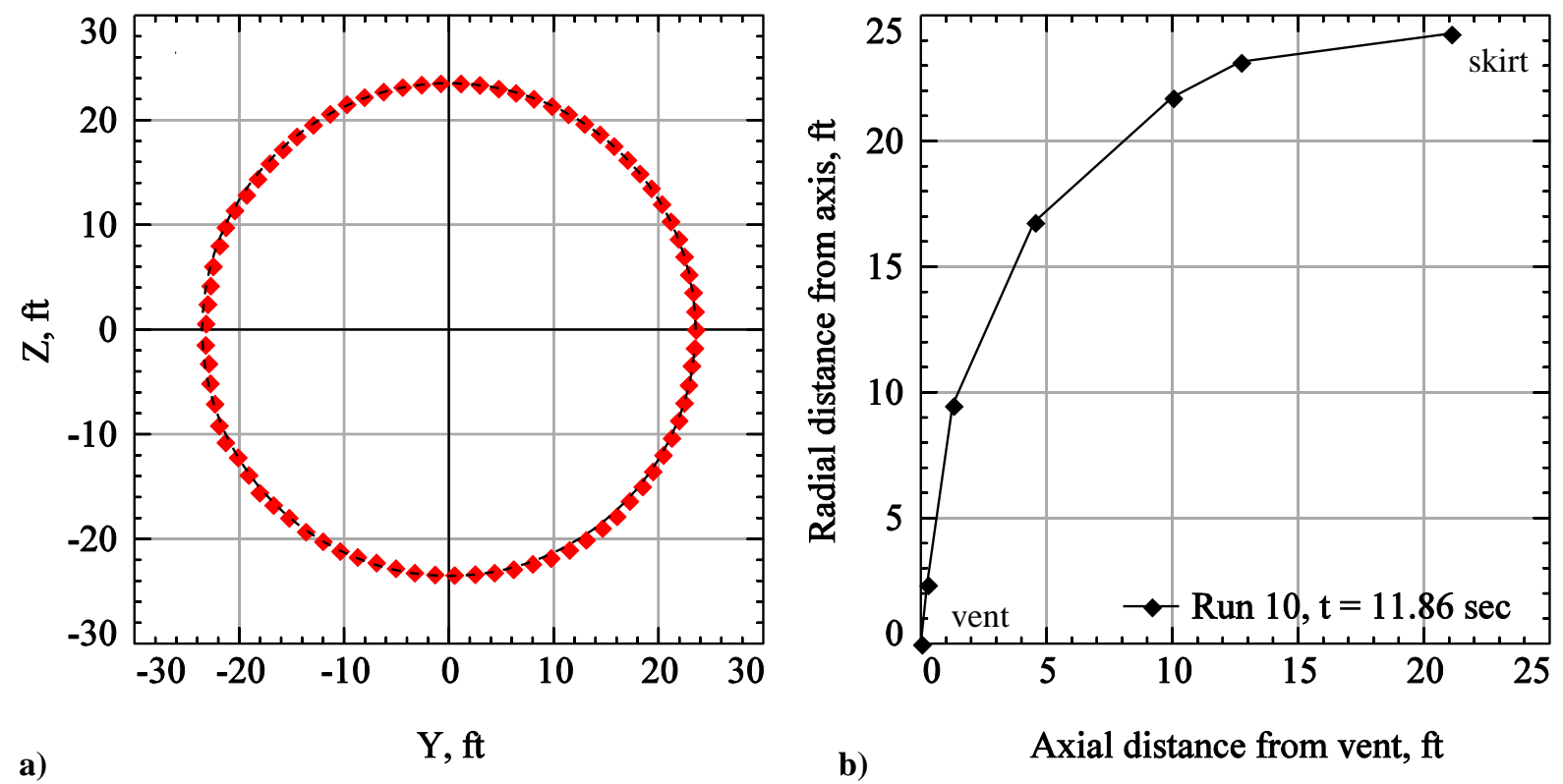

Fig. 27 Mars 2020 inflated parachute shape: a) Y-Z coordinates of skirt (red targets in Fig. 26); b) shape of gore (cyan targets in Fig. 26).

where the camera configuration was very similar to LDSD and CPAS but where there were no targets and the canopies were tracked manually by point and click, uncertainties in both the image- and object-space coordinates were at least several times as large as those for LDSD and CPAS. The uncertainties were even larger for the Mars 2020 

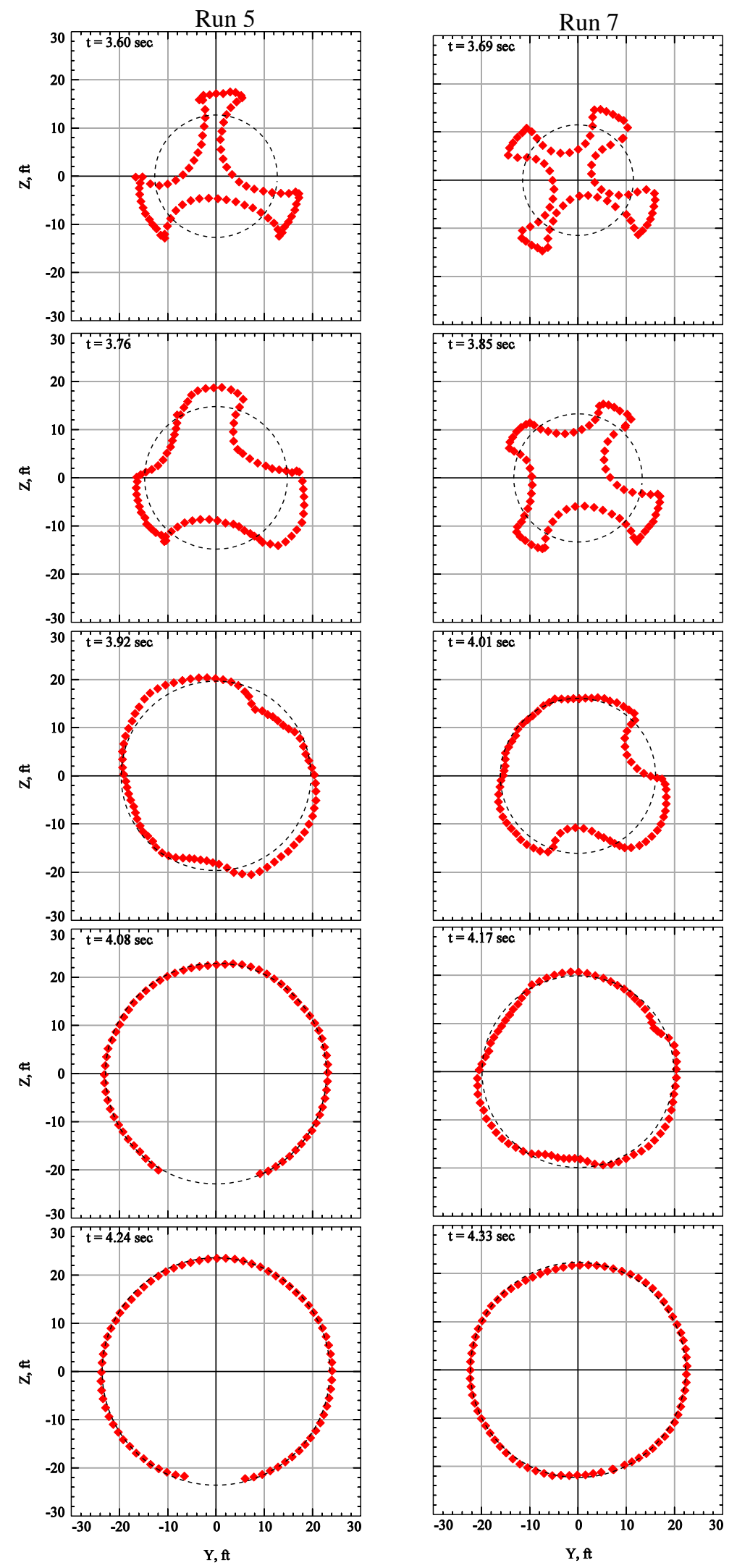

Fig. 28 Mars $2020 \mathrm{Y}-\mathrm{Z}$ coordinates of skirt during two mortar deployments at $q=16.3 \mathrm{psf}$. 
measurements due to greater uncertainty in both the spatial and image-plane positions of the tunnel features used to calibrate the cameras.

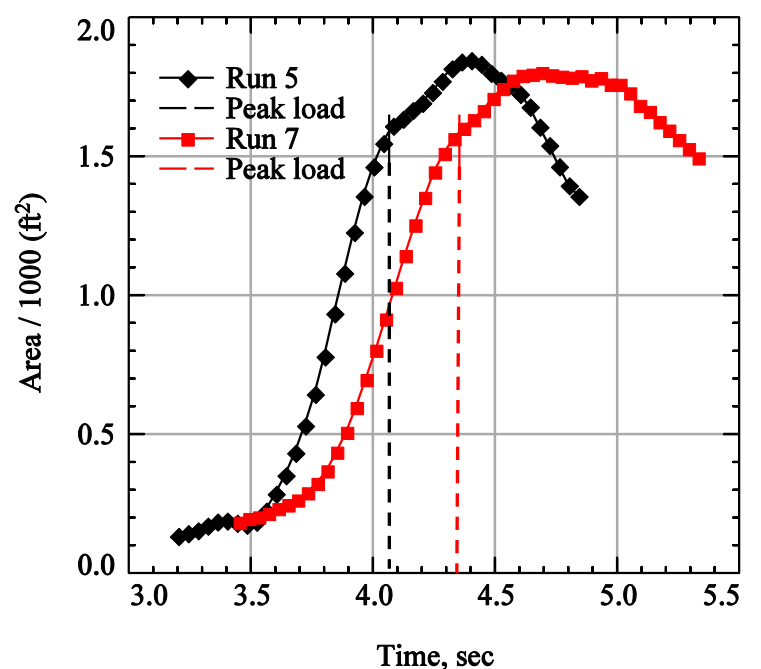

Fig. 29 Frontal area vs time of two mortar deployments at $q=16.3$ psf.

\section{Conclusion}

Photogrammetry was successfully applied in a series of parachute tests in the NFAC 80 - by 120 -ft wind tunnel. The measurements included time-histories of the pendulum motion of the parachutes about the riser attachment point (LDSD, CPA, Mars 2020); the diameter and longitudinal shape of the canopy (CPAS and Mars 2020); trajectories of mortar-deployed parachutes (InSight); and time histories of the inflation of the skirt (Mars 2020). Camera calibration at the huge scale of this test section was the most important challenge that had to be met. The time and effort required to calibrate the cameras ranged from very high for the first tests (LDSD and CPAS), where the spatial coordinates of targets were painstakingly measured with great accuracy by VSTARS, to very low for Mars 2020, where the positions of tunnel features were estimated with much less accuracy using only a tape measure.

\section{Acknowledgments}

The authors acknowledge the assistance of many people who participated in these tests. Special thanks to Jessica Powell of NASA/JSC for the analysis of the static CPAS data shown in Fig. 16; and Devon Kipp of JPL for the interpretation of InSight data shown in Fig. 20. For LDSD, thanks to Chris Tanner/JPL; Ian Clark/JPL; Patrick Goulding II/NFAC; and Al Witkowski/Pioneer Aerospace. For CPAS, thanks to Brian Anderson/NASA JSC; James Ross/NASA ARC; Jim Greathouse/NASA JSC; and Patrick Goulding II/NFAC. For InSight, thanks to Al Witkowski/Pioneer Aerospace; and for Mars 2020, thanks to Chris Tanner/JPL; Ian Clark/JPL; Chris Nykamp/NFAC; and James Ross/NASA ARC.

\section{References}

[1] Clark, I.G., Adler, M., and Rivellini, T.P., "Development and Testing of a New Family of Supersonic Decelerators,” AIAA Paper 2013-1252, March 2013.

[2] Lichodziejewski, D., et al., "Development and Testing of the Orion CEV Parachute Assembly System (CPAS)," AIAA Paper 2009-2938, May 2009.

[3] Witkowski, A., Buechler, D., and Kipp, D., "InSight Overview of the Parachute Decelerator System," 13 $3^{\text {th }}$ International Planetary Probe Workshop (IPPW-13), Laurel MD, July 2016. URL: https://solarsystem.nasa.gov/docs/IPPW13_03_PR_06_InSight_Overview_of_the_Parachute_Decelerator_System_A_Witkowski.pdf [retrieved 15 March 2018].

[4] URL: https/mars.nasa.gov/mars2020/ [retrieved 15 Mach 2018].

[5] URL: https://www.nasa.gov/centers/ames/news/features/2012/nfac-25html [retrieved 15 March 2018].

[6] Tanner, C.L., O'Farrell, C., and Ginn, J.M., 'Low-Density Supersonic Decelerators Wind Tunnel Testing of Various Parachute Configurations at the National Full-Scale Aerodynamics Complex (NFAC), Final Report”, JPL Document D-97596, Oct. 2016.

[7] Schairer, E.T., Heineck, J.T., Walker, S.M., and Yaste, D. M., "Predicting Camera Views for Image-Based Measurements in Wind Tunnels," AIAA Paper 2005-1349, Jan. 2005.

[8] Kushner, L.K., and Schairer, E.T., "Planning Image-Based Measurements in Wind Tunnels by Virtual Imaging," AIAA Paper 2011-0930, Jan. 2011.

[9] Abdel-Aziz, Y.I., and Karara, H.M, "Direct Linear Transformation from Comparator Coordinates into Object Space Coordinates," Proceedings of the Symposium on Close-Range Photogrammetry, Urbana, IL, Jan. 1971. 
[10] Brooks, J.D., and Beamish, J.K., "Measurement of Model Aeroelastic Deformations in the Wind Tunnel at Transonic Speeds Using Stereophotogrammetry," NASA TP 1010, 1977.

[11] Golub, G.H., and Reinsch, C., "Singular Value Decomposition and Least Squares Solutions," Numer. Math., Vol. 14, pp. 403420.

[12] Meyn, L.A., and Bennett, M.S., “A Two Camera Video Imaging System with Application to Parafoil Angle of Attack Measurements," AIAA Paper 91-0673, Jan. 1991.

[13] URL: https://www.geodetic.co/v-stars/ [retrieved 15 March 2018].

[14] Gonyea, K.C., Tanner, C.L., Clark, I.G., Kushner, L.K., Schairer, E.T., and Braun, R.D., "Aerodynamic Stability and Performance of Next-Generation Parachutes for Mars Descent," AIAA Paper 2013-1356, March 2013.

[15] Schoenenberger, M., Queen, E.M., and Cruz, J. R., "Parachute Aerodynamics from Video Data," AIAA Paper 2005-1633, May 2005.

[16] Tanner, C.L., Clark, I.G., Gallon, J.C., Rivellini, T.P., and Witkowski, A., “Aerodynamic Characterization of New Parachute Configurations for Low-Density Deceleration,” AIAA Paper 2013-1358, March 2013.

[17] Anderson, B.P., et al., "Subscale Parachute Test Results from the National Full-Scale Aerodynamic Complex 80- by 120-Ft Wind Tunnel in Support of Orion Parachute Pendulum Mitigation Activities," AIAA Paper 2017-4203, June 2017.

[18] Adams, D.S., and Onufer, N.P., "Mars Science Laboratory Parachute Development Test Program,” AIAA Paper 2011-2508, May 2011. 